\title{
Gas flow through clay barriers
}

\author{
S. OLIVELLA* and E. E. ALONSO*
}

\begin{abstract}
A model for the simulation of gas flow in clayey rocks and clays is described. Gas migration is associated with the development of preferential paths along existing or pressure-dependent discontinuities. The model handles the combined phenomena of two-phase (air and liquid) flow and the generation of discrete paths. Aperture of discrete paths is the main variable to account for permeability and capillary pressure variations. The model, which has been implemented in a general thermo-hydromechanical code, is used to simulate two experiments (laboratory and field). The laboratory experiment involved gas flow through shale specimens tested in a triaxial cell. In the field experiment, gas flow was forced through a sand-bentonite barrier. Experimental results and model calculations are compared in the paper.
\end{abstract}

KEYWORDS: case history; clays; numerical modelling; partial saturation; permeability; pore pressures; radioactive waste disposal
La présente communication décrit un modèle pour la simulation du flux de gaz dans des roches argileuses et des argiles. La circulation des gaz est associée au développement de chemins préférentiels le long de discontinuités existantes ou developée par la pression. Ce modèle traite les phénomènes combinés de l'écoulement biphasique (air et liquide) et de la production de chemins discrets. L'ouverture de chemins discrets est la principale variable tenant compte des variations de la perméabilité et de la pression capillaire. Le modèle, qui a été réalisé dans un code thermo hydromécanique général, est utilisé pour simuler deux expériences (en laboratoire et sur le terrain). L'expérience en laboratoire comportait un écoulement de gaz à travers des spécimens de schiste testés dans une cellule triaxiale. Lors de l'expérience sur le terrain, on a forcé un écoulement de gaz à travers une barrière de melange de sable de bentonite. Dans cette communication, on effectue la comparaison des résultats expérimentaux et des calculs sur des modèles.

\section{INTRODUCTION}

Current understanding of the physical phenomena taking place in an engineered clay barrier designed to isolate hazardous waste seems to provide a satisfactory answer to many questions that may be raised, both in design and in performance evaluation exercises. Theoretical and numerical developments, laboratory experimental research and largescale demonstration experiments have contributed to establishing a solid knowledge of the thermo-hydro-mechanical (THM) behaviour of compacted clay buffers and, more specifically, those integrated by compacted bentonite blocks (Alonso \& Ledesma, 2005).

Most of the research work performed on the THM behaviour of barriers concerns the initial transient processes of hydration under the combined action of the infiltrating water from the host rock and the heat generated by the canister (in the case of high-level nuclear waste). For obvious reasons, experimental information concerning this transient process covers only a minimum time period of the expected lifetime of an engineered barrier. In the demonstration project, FEBEX (Enresa, 2000) - probably the most complete largescale experiment conducted so far-'only' seven years of field data are currently available.

The long-term behaviour of clay barriers has received comparatively less attention. A significant issue in the longterm behaviour of clay buffers and the surrounding host rock concerns the generation and migration of gases due to waste decomposition, in the case of low- to medium-level nuclear waste, or canister corrosion, in the case of high-level waste (Gens et al., 2001; Alonso et al., 2002).

A large proportion of the experimental research performed concerns laboratory tests of gas flow through compacted

Manuscript received 24 January 2007; revised manuscript accepted 22 November 2007.

Discussion on this paper closes on 1 October 2008, for further details see p. ii.

* Department of Geotechnical Engineering and Geosciences, Universitat Politècnica de Catalunya, Barcelona, Spain. specimens, fully hydrated. They play the role of 'point' tests, although they can hardly be interpreted without due consideration of the development of preferential paths. Even at this small scale, the problem of path opening is part of the solution sought, and this situation presents a major difficulty for modelling work. Large-scale tests have rarely been conducted. The experience gained during the analysis of the large Gas Migration Test (GMT) performed at the Grimsel underground laboratory, located in the Swiss Alps, is one of the examples analysed later. This experiment has shown that test results are very sensitive to minor details, such as the presence of joints, interfaces or layer boundaries. From a theoretical standpoint, difficulties also arise because the classical framework for THM analysis, based on the solution of the equations of mass, heat and momentum balance in a porous medium, is insufficient to take into account the development of preferential gas paths through the barrier.

This paper first reviews some aspects of the mechanisms of gas transport in clays and clayey rocks. The model developed to simulate the concentrated flow of gas is then presented. It describes a procedure to model, in a unified manner, two-phase flow and concentrated gas flow through fractured porous rocks or engineered barriers. One advantage of the model is that it can be implemented, with limited effort, in general-purpose THM finite element codes such as CODE_BRIGHT (DIT-UPC, 2000).

A preliminary contribution by Alonso et al. (2006) contains a description of the model presented here and its application to simple examples, concerning a sample with a single fracture, and the study of gas flow in a simplified heterogeneous domain simulating the sand-bentonite buffer of the GMT test (described below). The formulation is presented here in more detail, and two experiments are analysed.

The performance of the model in simulating gas flow experiments on shale specimens confined in a triaxial cell is first described. The highly instrumented GMT test is then presented and simulated. The main idea behind the GMT test was to release pressurised gas from a concrete silo, 
located in a cylindrical excavation in granite. The space between the host rock and the silo was filled with a compacted sand-bentonite mixture. Water and gas injection stages were applied in a sequence of events described later. Particular attention was paid to the interfaces between the engineered barrier (the sand-bentonite mixture), the host rock and the silo. These interfaces also require specific treatment, similar to the way in which the joints of a fractured material are handled.

Model parameters were essentially based on the backanalysis of a few laboratory tests, which are also presented. Relevant field experimental results are interpreted and compared with model calculations.

\section{BACKGROUND}

Various mechanisms for gas migration have been identified-gas diffusion, two-phase flow and two-phase flow coupled with mechanical effects - that may lead to fracturing of the porous medium. In the third case, gas migration through advection along the highly pervious fracture is the dominant mechanism. The low permeability of engineered and geological barriers implies that the capillary pressure necessary to start desaturation (air entry pressure) will be high (small pore sizes). Then, under a given rate of gas generation, the gas pressure may increase, reaching values that may lead to gas fracture processes, or simply to gas flow through existing discontinuities that may undergo changes in their aperture. Modelling of gas flow under these conditions requires the introduction of mechanical formulations that make it possible to take into account fracture opening or fracture formation followed by subsequent opening. In such cases, fracture aperture is a key variable. Engineered and geological barriers may contain clay (compacted plastic clay is the preferred material for engineered barriers), and therefore swelling of the matrix is also an expected phenomenon during hydration phases.

Fluid flow in fractured rocks has been reported in the literature, mainly in the context of water flow. Olsson \& Barton (2001) have presented an improved model for hydromechanical coupling during shearing in rock joints. The model consists in a relationship between the actual aperture of the joint, which is referred to as the mechanical aperture, and the hydraulic aperture. The hydraulic aperture makes it possible to use a cubic law to determine the flow rate under a hydraulic gradient. According to experimental observations, the mechanical aperture is larger than the 'hydraulic' aperture (back-calculated from permeability measurements). This is motivated by the effect of roughness, which provides a reduction of permeability that, in the case of the cubic law, is ignored because a planar surface is assumed. The Olsson \& Barton model provides a relationship between the hydraulic conductivity and mechanical apertures via the JCR (joint roughness coefficient). In this context, coupling means that a hydraulic parameter is obtained from a mechanical parameter via a constitutive equation. Following this work, Lee \& Chou (2002) applied the model to investigate the hydraulic characteristics of rough fractures under normal and shear deformations of fractured granite and marble. Under normal loading, fracture permeability can be modelled through empirical relationships between normal stress and permeability. Under shearing loading, variations of permeability of two orders of magnitude were observed, which were attributed to aperture changes induced by dilation and to roughness variations due to gouge production.

Gas permeability of claystones has been reported in some experimental works. Zhang \& Rothfuchs (2004) described steady-state gas flow experiments on oven-dried specimens of a Callovo-Oxfordian argillite. They found that gas per- meability changes by one order of magnitude when flow parallel and perpendicular to bedding planes is compared. The effect of confining stress was, however, quite moderate. Steady-state gas flow experiments on oven-dried specimens of cretaceous marls and tertiary shales from the Swiss central Alps were also reported by Renner et al. (2000). They found a significant effect of confining stress (changes in intrinsic permeability of 1.5 orders of magnitude for a change of $30 \mathrm{MPa}$ of the confining stress). Permeability measured along schistosity planes was more than one order of magnitude higher than in other flow directions. The same authors report the effect of shear-straining on gas permeability measured by means of a transient decay pulse technique in a triaxial cell. Intrinsic permeability increases rapidly, during dilation, after the peak strength. Large changes in permeability induced by shearing (two orders of magnitude) were also reported by Uehara \& Shimamoto (2004) in tests of a cataclastic rock. All of these tests indicate the relevance of discontinuities to explain the measured changes of intrinsic permeability. In fact, if volumetric deformations are interpreted only as changes in porosity, the associated changes in permeability are very small. However, if global strains result in local changes in the opening of discontinuities, the permeability changes rapidly. This important consideration will be discussed later in more detail.

In the context of THM coupled processes in rocks including gas flow, the Yucca Mountain DST (drift scale test) experiment has been investigated in some detail (Datta et al., 2004). The drift scale test is an in situ heating test in a fractured tuff (Yucca Mountain) simulating a radioactive waste disposal scheme. In the DST test, THM processes are relevant, since the temperature reaches $200^{\circ} \mathrm{C}$ in the vicinity of the drift. Strong drying took place owing to evaporation, and a water front progressed towards the host rock. One way to observe the water saturation variations was to measure gas permeability at different points in space and time. The modelling activities carried out in the context of the DECOVALEX III projects (Rutqvist et al., 2005) have shown that mechanical effects may play a significant role in explaining the hydraulic behaviour. In fact, compression/dilatancy induced by heating implies gas permeability variations that were measured in the boreholes during the test. Details of a double-structure approach used to model this test are described in Olivella \& Gens (2005).

Data on gas permeability of compacted and natural clays has been reported (Volckaert et al., 1994; Romero et al., 2003).

The starting point for reporting results was often the following expression for Darcy's coefficient of permeability, $K$ :

$$
K=\frac{k k_{\mathrm{r}} \rho_{\mathrm{f}} g}{\mu_{\mathrm{f}}}
$$

where $k\left(\mathrm{~m}^{2}\right)$ is the intrinsic permeability; $k_{\mathrm{r}}$ is the relative permeability, $\rho_{\mathrm{f}}\left(\mathrm{kg} / \mathrm{m}^{3}\right)$ and $\mu_{\mathrm{f}}(\mathrm{Pa} \times \mathrm{s})$ are the density and viscosity of the permeating fluid; and $g(\mathrm{~N} / \mathrm{kg})$ is the gravitational force. The partial saturation of the soil is introduced through the coefficient $k_{\mathrm{r}}$. In the case of gas flow, $k_{\mathrm{r}}$ varies between 0 , when the degree of saturation $S_{\mathrm{r}}=1$, and 1 , when $S_{\mathrm{r}}=0$. Values of $k_{\mathrm{r}}\left(S_{\mathrm{r}}\right)$ have been reported in some of the references cited above.

Buffers for isolation of nuclear waste are very impervious materials that, in most design concepts, will reach saturation before any gas is released from the waste. A laboratory test mimicking the field situation may consist in raising the gas pressure on the upstream end of a saturated specimen until some flow through the specimen is detected. The rate of increase of gas pressure is controlled by the rate of inflow gas, which, in the real situation, depends on the type of 
waste and on the canister material, among other factors. Tests of this type have been reported by several authors, and a summary of the main aspects is given in Table 1. The table provides information on the type of compacted bentonite tested, its initial dry density, the flow imposed (either linear or radial in most cases), the controlling mechanism to impose a gas flow rate, and the confining conditions. Tests have been performed in a variety of cells (oedometric, isotropic, triaxial, constant volume). A common finding is that gas begins to flow once it has reached some pressure (the breakthrough pressure) that forces it through the specimen. Breakthrough times, breakthrough pressures, the evolution of gas inflow rates, upstream gas pressure and downstream flow rates are commonly reported. A frequent finding is that gas pressure reaches a marked peak at the time of breakthrough and then decreases. This behaviour has been interpreted (Horseman et al., 1999; Harrington \& Horseman, 2003) as an indication that, in these cases, gas essentially flows through preferential paths developed inside the matrix, induced by the gas pressure in a phenomenon similar to the more familiar hydraulic fracture mechanism.

In the tests reported in Table 1 the concepts of intrinsic and relative permeability, involved in equation (1), lose meaning, and alternative frameworks for gas flow have to be devised that respect the principles of two-phase flow in porous media when fracture opening does not take place. This is the main purpose of this paper.

\section{MODELLING DISCONTINUITIES IN COUPLED PROBLEMS}

The basic idea of the model presented here consists in the appropriate representation of single fractures embedded in a continuous finite element. Fig. 1 shows, on the left, a single fracture in a porous medium characterised by its aperture $b$ and, on the right, a finite element composed of a rock matrix (in general, a porous medium) and a series of $n$ fractures. The number of fractures in an element depends on the width $a$ associated with each fracture, which will be considered a characteristic size of the material, and on the element size $s$ (perpendicular to the direction of discontinuities).

Hydraulic and mechanical effects have to be included in

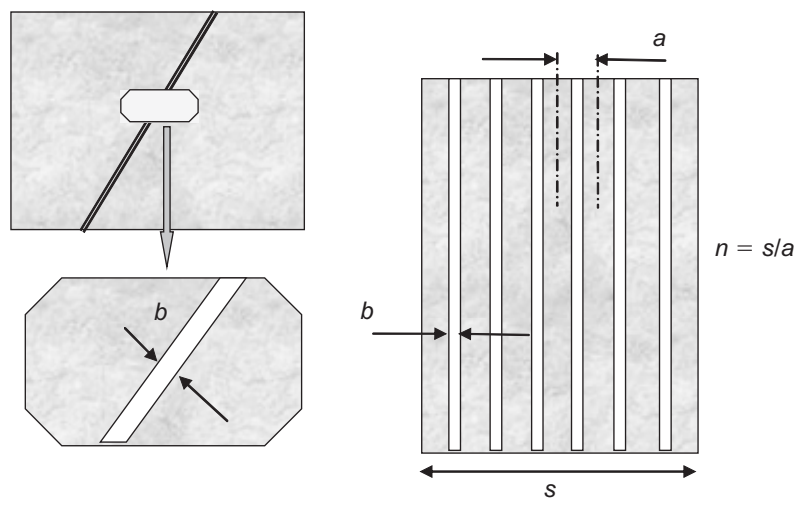

Fig. 1. Single fracture characterised by its aperture $b$ (left) and finite element with series of parallel fractures (right). Width of element is $s$, aperture of fractures is $b$, associated width to each fracture is $a$, and number of fractures in element is $n$

the formulation because gas flow depends critically on the mechanical interactions, since they control fracture aperture.

Consider first the flow through a single fracture. Liquid and gas flow will be calculated using Darcy's law. The intrinsic permeability can be calculated, assuming laminar flow, as

$$
k_{\text {fracture }}=\frac{b^{2}}{12}
$$

where $b$ is the aperture of the single fracture. In finite element applications the element size becomes a limitation for fracture modelling, because it is not convenient to use very thin elements. An alternative to the model presented in this paper is to consider explicit joint elements; an example is given by Gens et al. (1995) in the case of joints for mechanical purposes. Here homogenised properties are used because, in this way, it is possible to maintain, in a straightforward manner, the continuous approach to formulate coupled balance equations and the finite element discretisation.

When a set of $n$ fractures is included in a finite element

Table 1. Gas migration experiments in compacted bentonite

\begin{tabular}{|c|c|c|c|c|c|}
\hline Authors & Bentonite & $\begin{array}{l}\text { Dry density: } \\
\mathrm{Mg} / \mathrm{m}^{3}\end{array}$ & $\begin{array}{l}\text { Flow } \\
\text { geometry }\end{array}$ & Gas flow controls & Confining conditions \\
\hline $\begin{array}{l}\text { Pusch \& Forsberg } \\
\text { (1983) }\end{array}$ & MX80 & $\sim 1 \cdot 35-1 \cdot 65$ & Linear & $\begin{array}{l}\text { Constant pressure/pressure } \\
\text { increments }\end{array}$ & Constant-volume oedometer \\
\hline Pusch et al. (1985) & MX80 & $\sim 1 \cdot 1-1.78$ & Linear & Pressure increments & Constant-volume oedometer \\
\hline $\begin{array}{l}\text { Horseman \& Harrington } \\
\text { (1997) }\end{array}$ & MX80 & $1 \cdot 5-1 \cdot 7$ & $\begin{array}{l}\text { Linear } \\
\text { (axial) flor }\end{array}$ & $\begin{array}{l}\text { Displacement of gas by } \\
\text { water from upstream } \\
\text { reservoir }\end{array}$ & $\begin{array}{l}\text { Constant isotropic stress in flexible } \\
\text { sleeve subject to external fluid } \\
\text { pressure }(8-22 \mathrm{MPa})\end{array}$ \\
\hline $\begin{array}{l}\text { Horseman \& Harrington } \\
\text { (1997) }\end{array}$ & MX80 paste & $1 \cdot 3-1 \cdot 4$ & $\begin{array}{l}\text { Point source } \\
\text { and sink }\end{array}$ & $\begin{array}{l}\text { Displacement of gas by } \\
\text { water from reservoir }\end{array}$ & $\begin{array}{l}\text { Cylindrical pressure vessel with } \\
\text { confining pressure }(0 \cdot 8-2 \cdot 7 \mathrm{MPa}) \\
\text { imposed on floating end cap }\end{array}$ \\
\hline Tanai et al. (1997) & $\begin{array}{l}\text { Kunigel VI, } \\
\text { Fo-Ca Clay }\end{array}$ & $1 \cdot 4-1 \cdot 8$ & Linear & Pressure increments & Constant-volume cylinder \\
\hline Gallé (2000) & Fo-Ca Clay & $1.6-1.9$ & Linear & Pressure increments & Constant-volume oedometer cell \\
\hline Graham et al. (2002) & Avonlea & $0 \cdot 6-1 \cdot 4$ & Linear & Pressure increments & Constant-volume oedometer cell \\
\hline $\begin{array}{l}\text { Harrington \& Horseman } \\
\text { (2003) }\end{array}$ & MX80 & $1 \cdot 577-1 \cdot 582$ & $\begin{array}{l}\text { Radial, } \\
\text { central } \\
\text { source }\end{array}$ & $\begin{array}{l}\text { Displacement of gas by } \\
\text { water from upstream } \\
\text { reservoir }\end{array}$ & Constant-volume cylindrical vessel \\
\hline $\begin{array}{l}\text { Harrington \& Horseman } \\
\text { (2003) }\end{array}$ & MX80 & $1 \cdot 596$ & Linear & $\begin{array}{l}\text { Displacement of gas by } \\
\text { water from upstream } \\
\text { reservoir }\end{array}$ & $\begin{array}{l}\text { Cylindrical pressure vessel with } \\
\text { confining pressure }(10 \mathrm{MPa}) \\
\text { applied to floating end caps }\end{array}$ \\
\hline
\end{tabular}


(Fig. 1), the equivalent intrinsic permeability of the element in the direction parallel to the fractures can be calculated as

$$
\begin{aligned}
k & =k_{\text {matrix }}\left(\frac{s-n b}{s}\right)+\sum_{i=1}^{n}\left(k_{\text {fracture }} \frac{b}{a}\right) \\
& =k_{\text {matrix }}\left(\frac{s-n b}{s}\right)+\sum_{i=1}^{n}\left(k_{\text {fracture }} \frac{b}{a} \frac{1}{n}\right) \\
& \cong k_{\text {matrix }}+\frac{b^{3}}{12 a}
\end{aligned}
$$

where $k_{\text {matrix }}$ is the reference intrinsic permeability of the rock matrix or porous material, that is, the material without fractures; $s$ is the element size (width normal to flow direction); $a$ is the width associated with each fracture; and $n=s / a$ is the number of fractures in the element. The permeability of the matrix will be relevant only for very low apertures; otherwise, fracture permeability will dominate the total permeability, and matrix permeability will be negligible in comparative terms. Equation (3) shows that the element permeability does not depend on the size of the element but on the width associated with each fracture, $a$, which can be considered a characteristic parameter for a specific rock or porous material. The permeability perpendicular to the fractures is set equal to the matrix permeability.

The orientation of the discontinuities is assumed to be known at this stage. It can correspond to different situations such as

(a) bedding planes induced by rock sedimentation or buffer material compaction

(b) contact between different materials (e.g. between engineered barrier materials and/or host rock)

(c) cracks induced by thermal desiccation

(d) discontinuities determined by an appropriate mechanical constitutive model that determines them from stress and strain orientations.

In the latter two cases the criterion for fracture development corresponds to the mechanical constitutive model. However, it is not necessary to know the fracture orientation to apply the described method. In the simplest case, if conditions for fracture development are met at some particular position (finite element), and the change in fracture aperture is calculated, the overall permeability of this element may be changed in an isotropic manner. However, if the elements are small enough, a set of elements of increased permeability will indicate a preferential flow path. The development of these paths is controlled by the stress and strain states, and leads, in practice, to an induced flow anisotropy and heterogeneity. This is the approach followed in some of the applications presented below.

The second hydraulic process that is included in the fracture is the variation of capillary pressure induced by aperture changes. According to Kelvin's law, the capillary pressure necessary to desaturate a fracture is given by

$$
P_{0}=\sigma\left(\frac{1}{r_{1}}+\frac{1}{r_{2}}\right)=\frac{2 \sigma}{b}
$$

which is obtained when $\left(1 / r_{1}\right)=0$ and $r_{2}=b / 2$ (the wetting angle has been assumed to be 0 ). This equation can be used directly to calculate the air entry value of the element. If equation (4) is combined with equation (3), the capillary pressure to start desaturation is obtained as

$$
P=P_{0} \frac{\sqrt[3]{k_{0}}}{\sqrt[3]{k}}
$$

where $P_{0}$ is the capillary pressure for a reference permeability $k_{0}$, which eventually can be the initial permeability. As a first approximation, the capillary pressure associated with the discontinuity can be introduced in the standard water retention curve of van Genuchten (VG) (van Genuchten, 1980), which is written as

$$
S_{1}=\left[1+\left(\frac{\psi}{P}\right)^{\frac{1}{1-\lambda}}\right]^{-\lambda}
$$

where $S_{1}$ is the (liquid) degree of saturation; $\lambda$ and $P$ (given by equation (5)) are model parameters; and $\psi\left(=P_{\mathrm{g}}-P_{1}\right)$, the difference between the gas and liquid pressures, is the current suction. Without loss of generality, the parameter $P$ can also be scaled with surface tension calculated with different temperatures $\left(P=P_{0}\left(\sqrt[3]{k_{0}} / \sqrt[3]{k}\right)\left(\sigma / \sigma_{0}\right)\right)$.

From the mechanical point of view, the interest lies in the process of fracture formation and aperture changes. This information allows the calculation of the current intrinsic permeability. The effect of desaturation on permeability will be maintained through the concept of relative permeability, and a power law

$$
k_{\mathrm{rl}}=S_{1}^{n_{1}}
$$

will be adopted ( $n_{1}$ is a model parameter).

The aperture of the fracture can be estimated as a function of deformation from

$$
\begin{array}{ll}
b=b_{0}+\Delta b & \text { for } \Delta b \geqslant 0 \\
\Delta b=a \Delta \boldsymbol{\varepsilon}=a\left(\boldsymbol{\varepsilon}-\boldsymbol{\varepsilon}_{0}\right)=(s / n)\left(\boldsymbol{\varepsilon}-\boldsymbol{\varepsilon}_{0}\right) & \text { for } \boldsymbol{\varepsilon}>\boldsymbol{\varepsilon}_{0}
\end{array}
$$

It has been assumed that deformation is localised, and results in changes in aperture. A threshold value $\left(\boldsymbol{\varepsilon}_{0}\right)$ is considered. Therefore the changes in aperture start when deformation reaches this value. Deformation perpendicular to the fracture plane is to be used when aperture changes have to be obtained. The threshold value $\left(\varepsilon_{0}\right)$ is associated with fracture initiation. This parameter will be set to zero if the fractures already exist and have an initial aperture $b_{0}$. The initial aperture can be also zero when the fractures exist but are closed.

The stress-strain behaviour of the matrix, including fracture formation, is a crucial component of the aperture changes. If an elasto-plastic model is considered for the matrix mass behaviour, fracture initiation can be associated with tension stresses or with dilatancy. On the other hand, fracture orientation is sensitive to the stress tensor orientation, so the plane where the minimum principal stress (compression positive) occurs defines the plane of fracture formation.

Equation (8) is introduced into equation (3) to calculate the element permeability as

$$
\begin{aligned}
k & =k_{\text {matrix }}+\frac{b^{3}}{12 a} \\
& =k_{\text {matrix }}+\frac{\left[b_{0}+a\left(\boldsymbol{\varepsilon}-\varepsilon_{0}\right)\right]^{3}}{12 a}
\end{aligned}
$$

From this relationship it can be seen that the element permeability depends on the fracture spacing $a$, which is a characteristic size of the material, but it is independent of the element size $s$. In general, it will be of interest to consider $s \geqslant a$ (i.e. $n \geqslant 1$, one or more fractures in each element), because in this way some of the elements in the finite element mesh will develop higher permeability, owing to opening of the fractures contained in these elements. Other elements will maintain the properties of the intact 
rock or porous material. Consequently, preferential paths can be simulated. On the other hand, if $s<a$ (i.e. $n<1$, less than one fracture in each element), a single fracture would be homogenised into various elements, and an unsuitable smoothing of the preferential flow path would take place.

Using the preceding permeability (written here as a permeability tensor $\mathbf{k}$ ), the gas flux and the flow rate (discharge) of the element in the direction of the discontinuity are expressed as

$$
\begin{aligned}
\mathbf{k} & =\mathbf{I} k_{\text {matrix }}+\mathbf{n n}^{t} \frac{b^{3}}{12 a} \\
\mathbf{q} & =-\frac{\mathbf{k}}{\mu_{\mathrm{g}}}\left(\nabla p_{\mathrm{g}}+\rho g \nabla z\right) \\
& =-\frac{1}{\mu_{\mathrm{g}}}\left(\mathbf{I} k_{\text {matrix }}+\mathbf{n n}^{t} \frac{b^{3}}{12 a}\right)\left(\nabla p_{\mathrm{g}}+\rho g \nabla z\right) \\
Q & =\mathbf{n}^{t} \mathbf{q} s=-\mathbf{n}^{t} \frac{1}{\mu_{\mathrm{g}}}\left(s \mathbf{I} k_{\text {matrix }}+\mathbf{n n}^{t} \frac{s b^{3}}{12 a}\right)\left(\nabla p_{\mathrm{g}}+\rho g \nabla z\right) \\
& =-\mathbf{n}^{t} \frac{\mathbf{T}}{\mu_{\mathrm{g}}}\left(\nabla p_{\mathrm{g}}+\rho g \nabla z\right)
\end{aligned}
$$

where the vector $\mathbf{n}$ gives the direction parallel to the discontinuity; I is the identity matrix; $\mathbf{q}$ is the flux of gas; and $s$ is the element size perpendicular to the discontinuity. $\mathbf{T}$ is the intrinsic transmissivity matrix $\left(\mathrm{L}^{3}\right)$. It can be observed that the discharge depends only on the fracture intrinsic transmissivity, defined as intrinsic permeability times the element width. The implementation of the model in a finite element program implies that flux $\mathbf{q}$ is introduced in the mass balance of gas. This flux is converted into a mass flux simply by multiplication by the gas density, calculated for instance through the law of ideal gases. The flow rates are obtained after application of the finite element approach. Here the flow rate in the discontinuity direction is written only to demonstrate that it could be expressed as a function of a transmissivity function.

If the matrix permeability is neglected in the direction of the discontinuity (as compared with the effect of the cubic law), the flow rate in the direction parallel to the discontinuity is expressed as

$$
Q=-\frac{s b^{3}}{12 a \mu_{\mathrm{g}}} \mathbf{n}^{t}\left(\nabla p_{\mathrm{g}}+\rho g \nabla z\right)
$$

which depends on the number of fractures in the element $(s / a=n)$ and their aperture $(b)$.

Figure 2 shows the general stress-strain behaviour coupled to aperture changes in the case of tension taking place. A threshold strain $\left(\varepsilon_{0}\right)$ defines the initiation of fracture aperture. Failure is achieved when the normal stress reaches the matrix tensile strength $\sigma_{\mathrm{t}}$; at this stage a failure strain $\varepsilon_{1}$ is derived from the selected constitutive model for the porous matrix.

The following cases can be established.

(a) Existing fracture:

$$
\begin{gathered}
\sigma_{\mathrm{t}}=0, \varepsilon_{0} \approx 0 \text { (initially closed) } \\
\text { or } \varepsilon_{0}<0 \text { (initially open) }
\end{gathered}
$$

(b) Non-existing fracture:

$$
\sigma_{\mathrm{t}} \neq 0 \text { and } \varepsilon_{0}=\varepsilon_{1} \neq 0
$$

The first case $(a)$ corresponds to a fracture that, owing to compression stresses, is closed (for $\varepsilon_{0} \approx 0$ ) or has an initial

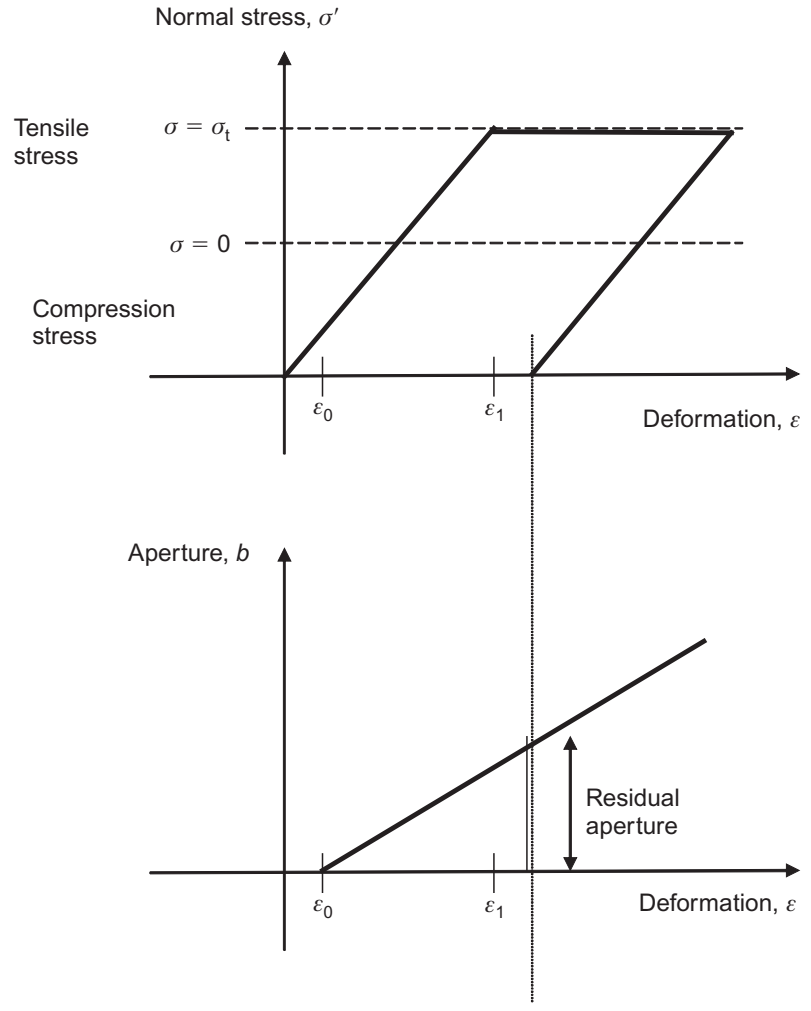

Fig. 2. Stress-strain behaviour under normal stress changes coupled to fracture aperture changes

aperture $\left(\boldsymbol{\varepsilon}_{0}<0 \Rightarrow b=b_{0}+(s / n)\left(-\boldsymbol{\varepsilon}_{0}\right)>b_{0}\right)$. Normal extension will induce aperture opening right from the beginning of stressing (because $\varepsilon>\varepsilon_{0}$ ). As the normal stress reaches a zero value (because $\sigma_{\mathrm{t}}=0$ ), deformation will increase under constant stress. Unloading will imply fracture closure, but a residual aperture is expected in a general case, owing to irreversible deformations.

The second case $(b)$ implies that a tensile strength exists, and therefore aperture opening cannot be initiated before failure by tension occurs. For this reason the threshold strain $\left(\varepsilon_{0}\right)$ is equal to the strain corresponding to failure $\left(\varepsilon_{1}\right)$. This latter value depends on the tensile strength.

Another situation arises when dilatancy is induced by shearing. In this case the formation of fractures is due to extension, which is a consequence of dilatancy. Again, the threshold strain is convenient for defining the initiation of fracture opening.

Fractures induced by tension and fractures induced by dilatancy, even though they are physically different processes, are considered in a unified manner in elasto-plastic models. In fact, extension induced by tension or extension induced by dilatancy depend essentially on the stress path followed. The model outlined has been implemented in CODE_BRIGHT (Olivella et al., 1995; DIT-UPC, 2000), which was used to simulate all the cases presented in this paper. CODE_BRIGHT is a finite element model that solves the coupled equations of mass, momentum and energy balance in porous media. In the gas flow part it uses the law of ideal gases, and it includes the solubility of the gas in the liquid phase via Henry's constant. Gas and water vapour can be considered as an ideal mixture (including diffusion and dispersion), and the effect of Knudsen diffusion can be taken into account through a modification of the gas viscosity (using a function of gas pressure and permeability), which in turn leads to an increase in gas flow. The Appendix summarises the set of field equations solved in the model, 
and provides some details of the formulation for the gas flow.

\section{MODEL PERFORMANCE}

In order to show the capabilities of the model, consider in Fig. 3(a) the behaviour of a porous specimen with a vertical fracture zone, which may open when tensile strains develop. The idealised case represents a $20 \times 20 \mathrm{~cm}^{2}$ planar sample, initially saturated, which is subjected to gas injection through the bottom boundary. The fracture zone is discretised by means of porous elements incorporating the formulation just described. The remaining part of the specimen (the matrix) will be represented by a standard porous material. The discretised specimen is shown in Fig. 3(b). Mechanical effects are incorporated both in the central elements and in the remaining porous matrix by means of an elasto-plastic model whose parameters are given in Table 2. A very small (or nil) tensile strength characterises the fracture zone. However, a significant tensile strength $(1 \mathrm{MPa})$ characterises the porous matrix. The table also provides the hydraulic parameters used in the example. When gas is injected through the lower boundary the specimen is expected to become partially saturated in a progressive way. Gas pressure build-up is also expected to open a central fracture and to develop a preferential flow path.

The calculated response of the sample to gas injection is shown in Figs 3(c) and 3(d). Two cases are considered. In the first case (Fig. 3(c)) the fracture already exists in the sample, and it may open. This means that the elements in the fracture zone do not resist any tensile strength. As extension takes place in the fracture elements, the fracture opens, and the permeability increases. By contrast, the second case (Fig. 3(d)) is characterised by a material that

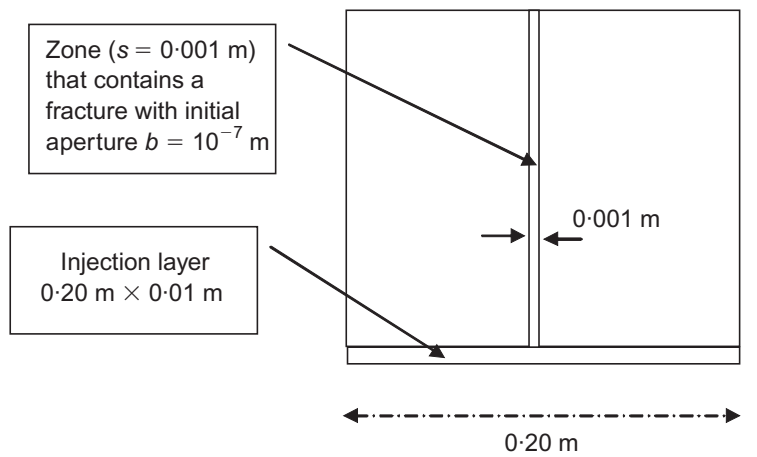

(a)

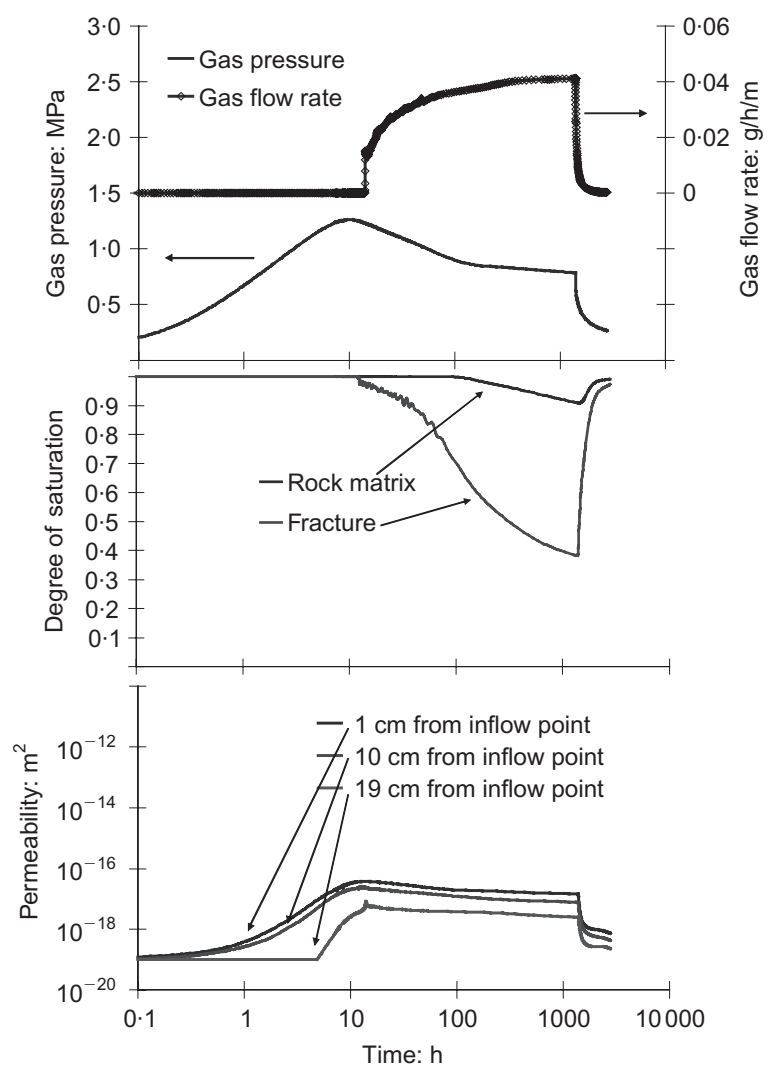

(c)

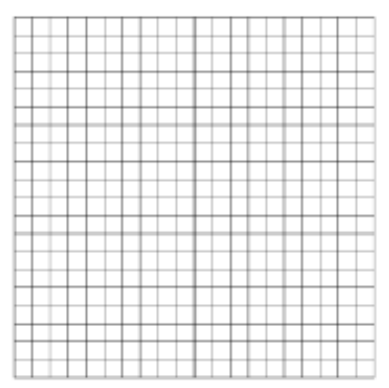

(b)

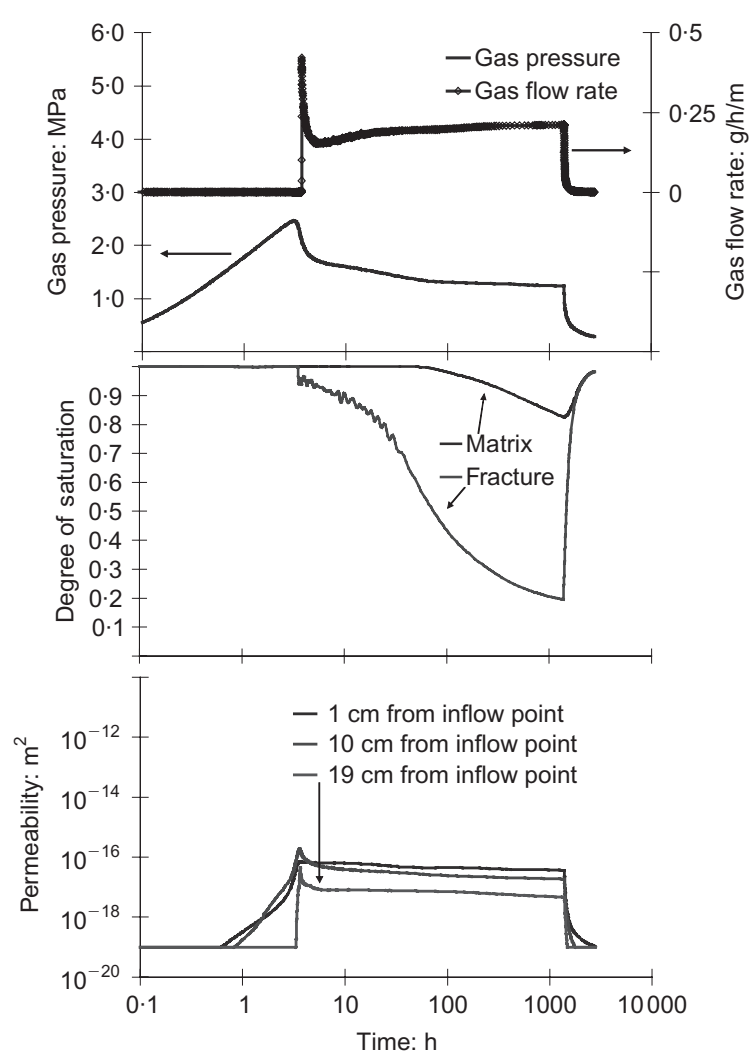

(d)

Fig. 3. Typical response of fracture element when included in a sample: (a) sample representation; (b) finite element mesh; (c) sample containing a fracture initially closed; (d) sample containing an element that may develop a fracture 
Table 2. Parameters for model performance examples

\begin{tabular}{|c|c|c|}
\hline Parameter & Performance model & Model for Rummel-Weber tests \\
\hline $\begin{array}{l}\text { Porosity } \\
\text { Intrinsic permeability of rock matrix: } \mathrm{m}^{2} \\
\text { Retention curve } P_{0} \text { in VG model: MPa } \\
\text { Retention curve } \lambda \text { in VG model } \\
\text { Relative permeability, } n_{1} \\
\text { Elastic parameters } \\
v=\frac{3 K-2 G}{6 K+2 G} \\
E=3 K(1-2 v) \\
\text { Slope of critical-state curve, } M \\
\text { Preconsolidation stress for yield curve } \\
\text { in critical-state model, } p_{0} \\
\text { Isotropic elasto-plastic compression } \\
\text { index, } \lambda \\
\text { Tensile strength rock matrix, } p_{\mathrm{s}} \\
\text { Tensile strength for fractured zone, } p_{\mathrm{s}} \text { : } \\
\text { MPa } \\
\text { Threshold strain, } \varepsilon_{0} \\
\text { Swelling parameter, } k_{\mathrm{s}}\end{array}$ & $\begin{array}{c}0 \cdot 11 \\
10^{-19} \\
0 \cdot 3 \\
0 \cdot 50 \\
3 \\
K=1000 \mathrm{MPa} \\
G=800 \mathrm{MPa} \\
v=\frac{3 \times 1000-2 \times 800}{6 \times 1000+2 \times 800}=0 \cdot 2 \\
E=1800 \mathrm{MPa} \\
1 \\
20 \\
0 \cdot 05 \\
10 \mathrm{MPa} \\
0 \cdot 0 \text { (existing fracture); } 0 \cdot 5 \text { (new fracture) } \\
0 \cdot 0001 \\
0\end{array}$ & $\begin{array}{l}1 \\
\text { Random distribution with average value of } \\
133 \mathrm{MPa} \text { and standard deviation of } 3.6 \mathrm{MPa} \\
\text { (no spatial correlation) } \\
0.05 \\
10 \mathrm{MPa} \\
0 \text { (only for case with predefined fracture); } \\
10 \text { for heterogeneous sample } \\
0.00001 \\
0.005\end{array}$ \\
\hline
\end{tabular}

The curve $q^{2}=M^{2}\left(p_{0}-p^{\prime}\right)\left(p+p_{\mathrm{s}}\right)$ was used to determine strength and calculate dilatancy.

has a certain tensile strength $(0.5 \mathrm{MPa})$, lower than the tensile strength of the matrix. A certain deformation is required to start fracture opening. This deformation corresponds to the deformation in extension required to reach fracture in tension. In this example the following threshold values were selected: $\varepsilon_{1}=0.001$ and $\varepsilon_{0}=0.0001$.

For both examples the confining stress is $1 \mathrm{MPa}$ (horizontal), and the initial pressure of water and gas is $0 \cdot 1 \mathrm{MPa}$ (atmospheric pressure). Gas flow rates at injection point were fixed at $0.0432 \mathrm{~g} / \mathrm{h}$ and $0.216 \mathrm{~g} / \mathrm{h}$ for the first and second cases respectively. Figs $3(\mathrm{c})$ and $3(\mathrm{~d})$ show the evolution of gas pressure at the injection point and the gas flow rate at the outflow point. After a period of gas pressure increase, which corresponds to the desaturation of the injection layer, gas starts to penetrate in the medium. Both tests show a gas pressure build-up and a peak threshold pressure. However, there is a substantial difference in the evolution of outflow rate of gas. In the second case a distinct peak is calculated at breakthrough. This behaviour is explained because the tensile strength adds an additional resistance to open the fracture zone. The evolution of degree of saturation at two representative points of the fracture zone is also given in Figs 3(c) and 3(d). Desaturation is easier in the fracture zone than in the matrix. Because of the fracture aperture, permeability increases substantially at different points of the fracture zone. In both cases steady state is effectively reached after $1000 \mathrm{~h}$. Then gas injection is stopped, and the gas pressure drops accordingly.

The question of the determination of the gas pressure inducing the first passage of gas (the peak gas pressure) has a practical importance. If the gas starts desaturation of the initially saturated porous material, it will enter the matrix if the minimum principal effective stress becomes zero. If, after gas penetration, the effective stress is defined as the excess of total stress over gas pressure, then the gas pressure leading to fracture opening in the first case (no tensile strength) could be calculated as confining stress + backpressure $=1 \cdot 0+0 \cdot 1=1 \cdot 1 \mathrm{MPa}$ (which should be compared with the calculated peak gas pressure of $1.25 \mathrm{MPa}$; Fig. $3(\mathrm{c}))$. However, in order for the gas to enter, it has to overcome the air entry value (0.3 MPa). This is a different process, purely hydraulic and associated with the size and geometry of largest pores. The calculated peak pressure in this case lies between a value of $1 \cdot 1 \mathrm{MPa}$ and $1 \cdot 1+0 \cdot 3=$ $1.4 \mathrm{MPa}$ (if the air entry value is added to the 'mechanical' criterion). In the second example (a tensile strength of $1 \mathrm{MPa}$ is now added to the confining stress) the two limit values previously calculated become $2 \cdot 1$ and $2 \cdot 4 \mathrm{MPa}$, which are again close but below the calculated peak gas pressure (Fig. 3(d)). It should be added that, in the example run, pressure build-up takes place locally, near the injection point, and local two-dimensional effects complicate the simple criteria described.

Further investigations at this level (synthetic examples) to understand the different responses of the fracture element have been presented in Olivella \& Alonso (2002) and Alonso et al. (2006).

\section{GAS INJECTION TESTS IN A ROCK SAMPLE}

Rummel \& Weber (2000) carried out a series of simultaneous triaxial and gas flow tests in samples of Opalinus clay, a clay shale from Monterri, Switzerland. Test results were interpreted in terms of evolution of the coefficient of permeability as samples underwent a given protocol of loading, wetting and gas flow tests.

Sample intrinsic permeabilities were determined at different times during the test. The following values were reported by Rummel \& Weber (2000): intact sample, $5.2 \times 10^{-19} \mathrm{~m}^{2}$; broken sample, $1.2 \times 10^{-16} \mathrm{~m}^{2}$; beginning of water injection, $1.0 \times 10^{-18} \mathrm{~m}^{2}$; end of water injection, $4.0 \times 10^{-20}$ $\mathrm{m}^{2}$.

However, these tests provide more comprehensive information, which is useful for validating the model described. One of the interesting outcomes of these tests is that forced hydration, once the sample has been damaged by a previous deviatoric loading, induces fracture sealing. In order to account for swelling and drying effects, a simple non-linear elastic law was introduced to account for the volumetric deformations induced by suction changes,

$$
\mathrm{d} \varepsilon_{\mathrm{v}}=-k_{\mathrm{s}} \frac{d \psi}{\psi+p_{\mathrm{atm}}}
$$

where $p_{\text {atm }}$ is the atmospheric pressure, taken as a reference 
value, and $k_{\mathrm{s}}$ is a swelling/shrinkage coefficient. Otherwise, a critical-state elasto-plastic model, whose parameters are listed in Table 2, was selected to model the shale matrix. For the failure envelope a large preconsolidation stress was considered to represent a rock-like material. In this way, the yield curve in the dilatant part is conceptually similar to a Mohr-Coulomb envelope.

The dimensions of the discretised domain are $0.04 \mathrm{~m} \times$ $0.02 \mathrm{~m}$, which corresponds roughly to the actual dimensions of the cores used by Rummel \& Weber (2000) (diameter $0.030 \mathrm{~m}$ and length ranging between 0.030 and $0.060 \mathrm{~m}$ ). The intrinsic matrix permeability was selected as $10^{-19} \mathrm{~m}^{2}$ on the basis of the values reported in the preceding table for the beginning of the test and for the end of water injection (once the specimen was saturated). The selected initial aperture of the fracture is very small $\left(10^{-7} \mathrm{~m}\right)$, so it is practically closed, and the initial permeability provides a value of $10^{-19} \mathrm{~m}^{2}$, that is, the same as in the rock matrix. In a first representation of the test (Case A), the fracture is embedded in a zone that has a size of $0.6 \mathrm{~mm}(s=$ $0.0006 \mathrm{~m}$ ) wider than the aperture of the fracture. In other words, it is assumed that there is a central zone that will develop higher permeability as the fracture opening progresses. Permeability increases significantly in the vertical direction of the central zone only.

Specimens were initially unsaturated, although no precise information on the drying processes experienced by the specimen, prior to testing, is available. Specimens were initially compressed under a stress state $\left(\sigma_{3}=5 \mathrm{MPa} ; \sigma_{1}=\right.$ $7.5 \mathrm{MPa}$ ) far from failure conditions. The following sequence of events was then applied (see Figs 4 and 6 for further reference).

(a) A gas pulse test was initially performed. This stage was intended for permeability determination under undamaged conditions.

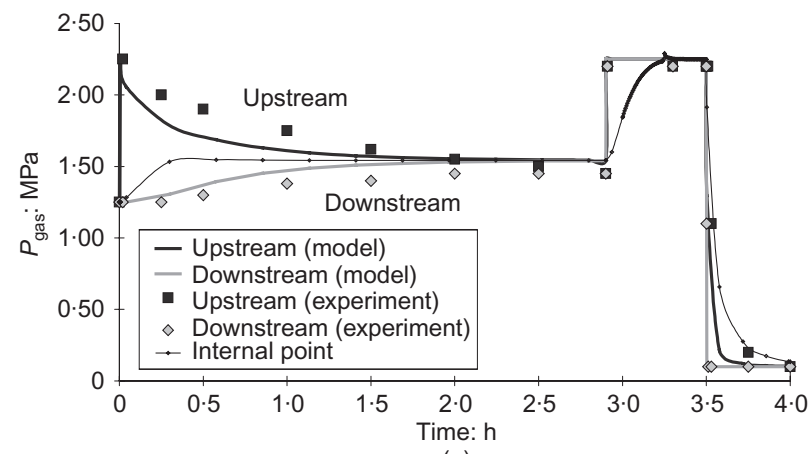

(a)

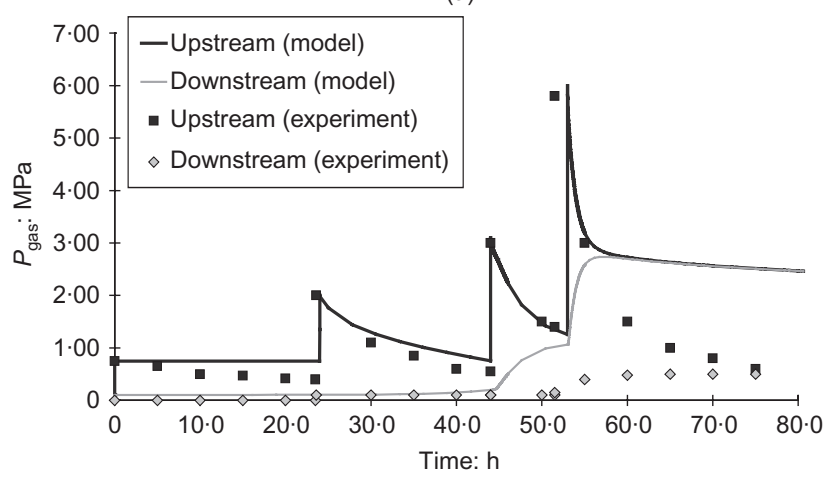

(b)

Fig. 4. Simulation of Rummel \& Weber test using sample with predefined zone with fracture elements (Case A): (a) gas pulse tests before and after fracture generation in dry sample; (b) gas pulse tests after sample inundation (Experimental results from Rummel \& Weber, 2000) (b) The vertical stress was increased to a value close to $80 \mathrm{MPa}$ and a fracture was generated in the specimen (time interval $3-3 \cdot 5 \mathrm{~h}$ ). A gas pulse test was simultaneously performed on the broken specimen. The vertical stress was then decreased to its initial value.

(c) Water injection was applied, with the purpose of sealing the fracture (Opalinus clay swells when it is hydrated). The specimen became saturated.

(d) A final gas pulse test was performed to investigate the final conditions of the sample, after hydration. A series of gas pulse tests were applied at this stage.

Figure 4(a) shows the first stage of the test for Case A (i.e. predefined fracture situation). Fracture is generated by means of the deviatoric stress application between 3 and $3.5 \mathrm{~h}$ from test initiation. Gas pulse tests were performed before, during and after fracture generation. It can be observed that the velocity of gas pressure dissipation is much higher after the fracture development. In a second test stage the sample was flooded with water, and pressurised until full saturation was achieved.

The experiment indicates that water saturation leads to a reduction of permeability. This is a process that can be a consequence of swelling of the material. In this case, only a single vertical central fracture was allowed. At the end of the shearing phase the model developed a zone with high permeability, but the remaining rock was intact. The hydration phase consisted of a series of pressurisation and depressurisation stages. The sample reached full saturation, expanded owing to the reduction of suction and, as a consequence, the permeability was reduced. Fig. 4(b) shows the results of gas pulse tests under hydrated conditions. The first and second gas tests are well reproduced, and the permeability reduction is clear: the fracture closed owing to swelling of the rock matrix, and the global permeability of the sample went back to the original minimum permeability, set by the matrix permeability $\left(10^{-19} \mathrm{~m}^{2}\right)$. Matrix swelling helped to model the observed reduction of gas permeability in a satisfactory manner. In Case A the permeability in the sample is $10^{-19} \mathrm{~m}^{2}$ initially; then it increases to $1.1 \times$ $10^{-16} \mathrm{~m}^{2}$ (obtained by averaging matrix and fracture values along the sample width, i.e. $\left.\left[(s-b) k_{\text {matrix }}+b k_{\text {fracture }}\right] / s\right)$; and during hydration it goes back to $10^{-19} \mathrm{~m}^{2}$. The measured value in the broken conditions was $1.2 \times 10^{-16} \mathrm{~m}^{2}$, as given above.

Modelling this test is a challenging task, and different degrees of modelling complexity were attempted. In a second computation (Case B) it was assumed that each point (i.e. each element) within the entire discretised domain could develop a fracture, and therefore the orientation and flow path development was a question of orientation and alignment of elements that develop higher permeability, which in turn depends on changing stress conditions. The effect of the discontinuity in each element is considered isotropic: that is, the permeability increases in all directions when the discontinuity appears in the element. A slight heterogeneity was also introduced, assigning random strength parameters to the finite elements (no spatial correlation was assigned to the initial conditions). A small variability around mean values was used in the generation of strength parameters (see Table 2). Calculated gas pressure at the injection point has been included in Fig. 5, together with experimental results. The agreement is quite satisfactory. In this case, strain localisation developed in the specimen during application of the deviatoric loading. Fig. 6 shows the evolution of porosity, permeability and gas fluxes in the sample during the shearing phase. While porosity changes slightly, permeability undergoes changes of several orders of magnitude. This variation is crucial if the gas pressure evolution ob- 


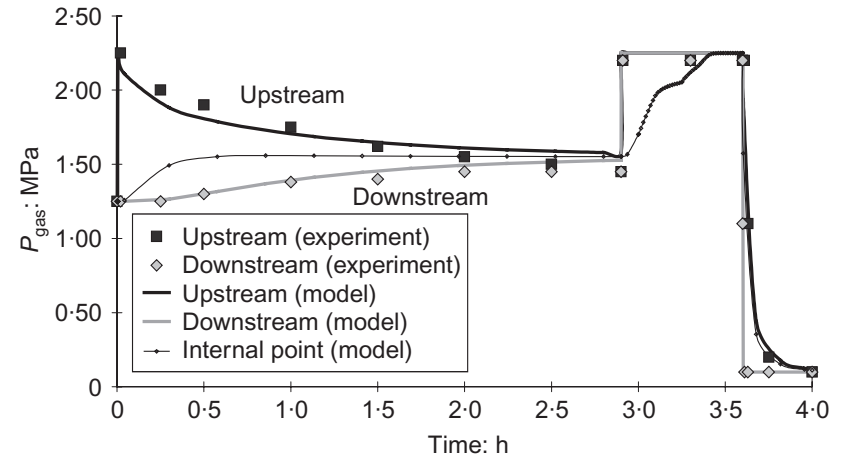

Fig. 5. Gas pulse tests before and after fracture generation in dry sample for analysis considering a random strength (Case B). Fracture is induced by deviatoric stress application between 3 and $3 \cdot 5 \mathrm{~h}$ (Experimental results from Rummel \& Weber, 2000)

served in the sample before and after failure is to be reproduced. Before failure, the pressure decays slowly (between 0 and $3 \mathrm{~h}$ ); however, the dissipation of pressure is very fast after failure (between 3.6 and $4 \mathrm{~h}$ ). In Case B the permeability in the sample is $4 \times 10^{-19} \mathrm{~m}^{2}$ initially; then it increases to $1.08 \times 10^{-16} \mathrm{~m}^{2}$, a value obtained by averaging all element permeabilities along the sample. The measured value in the broken conditions was $1.2 \times 10^{-16} \mathrm{~m}^{2}$, as given above.

The two calculations developed illustrate the possibilities of the proposed modelling approach. Further validation will now be presented at the scale of a large in situ test.

\section{MODELLING THE GAS MIGRATION TEST (GMT) \\ Description of the test}

Figure 7 shows a schematic diagram of the GMT test, in which several water and gas flow experiments were performed in a sequence during the period June 1998 to June 2004. The centre of the installation is occupied by a concrete silo, which is surrounded by a sealing material (a compacted sand-bentonite mixture, which constitutes the engineered barrier system (EBS)). Silo and barrier occupy a vertical shaft excavated in granite. The upper part of the cavern was filled with a mixture of sand and gravel placed directly on the upper layer of the compacted sand-bentonite. The scale of the GMT experiment is about 1:10 compared with the reference silo foreseen for waste disposal. Gas is to be injected at the centre of the silo, simulating gas generation by decomposition of organic matter. The behaviour of the sand-bentonite compacted mixture was monitored in detail. The test has radial symmetry around the central vertical axis, except for the access drift (backfilled with sand

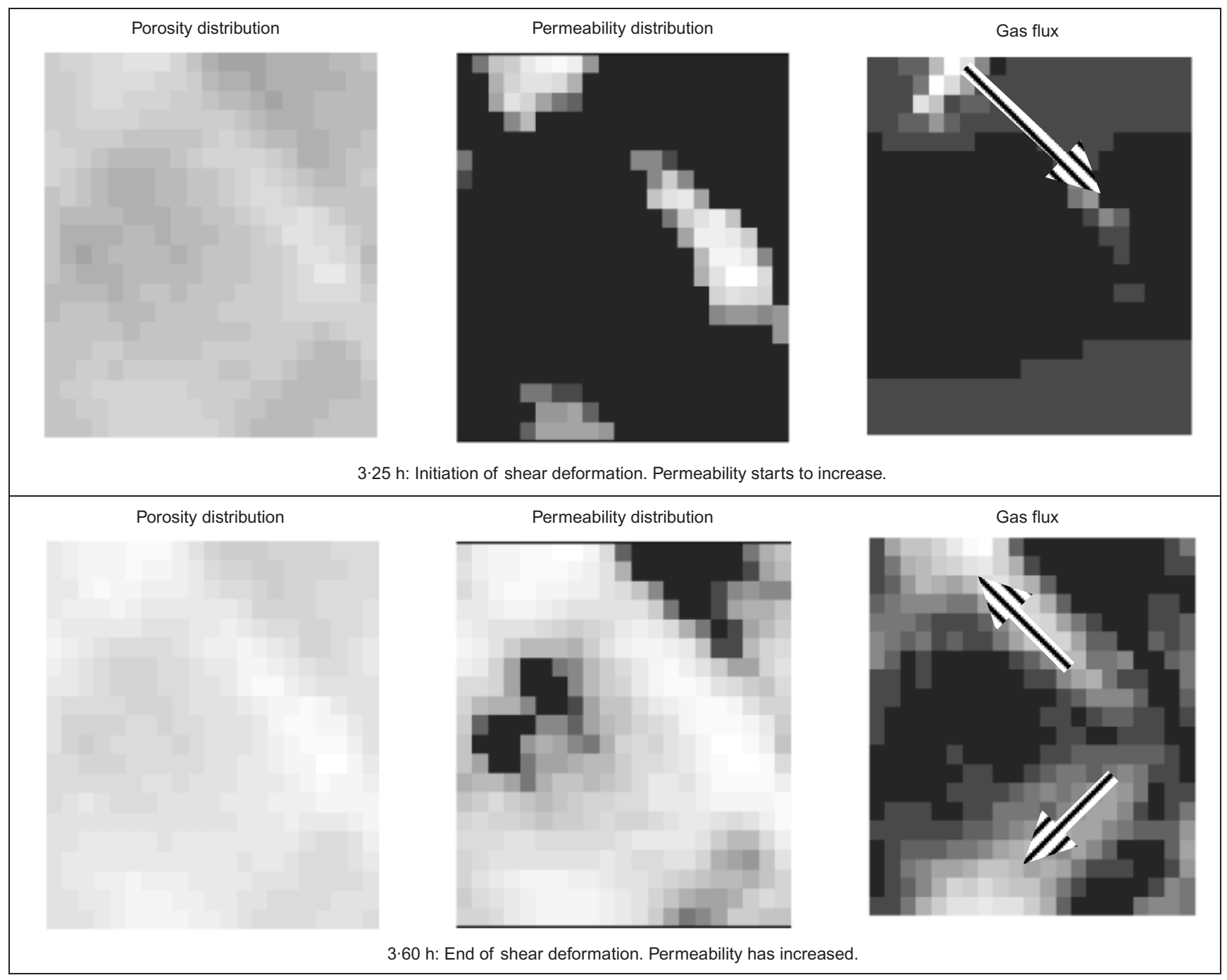

Fig. 6. Evolution of several variables during distributed fracture induced by deviatoric stress application (white zones are zones of higher porosity, ranges from $0 \cdot 105$ to $0 \cdot 116$ ), permeability (ranges from $10^{-19}$ to $10^{-15} \mathrm{~m}^{2}$ ) and gas flux. Analysis considering a random strength (Case B) 


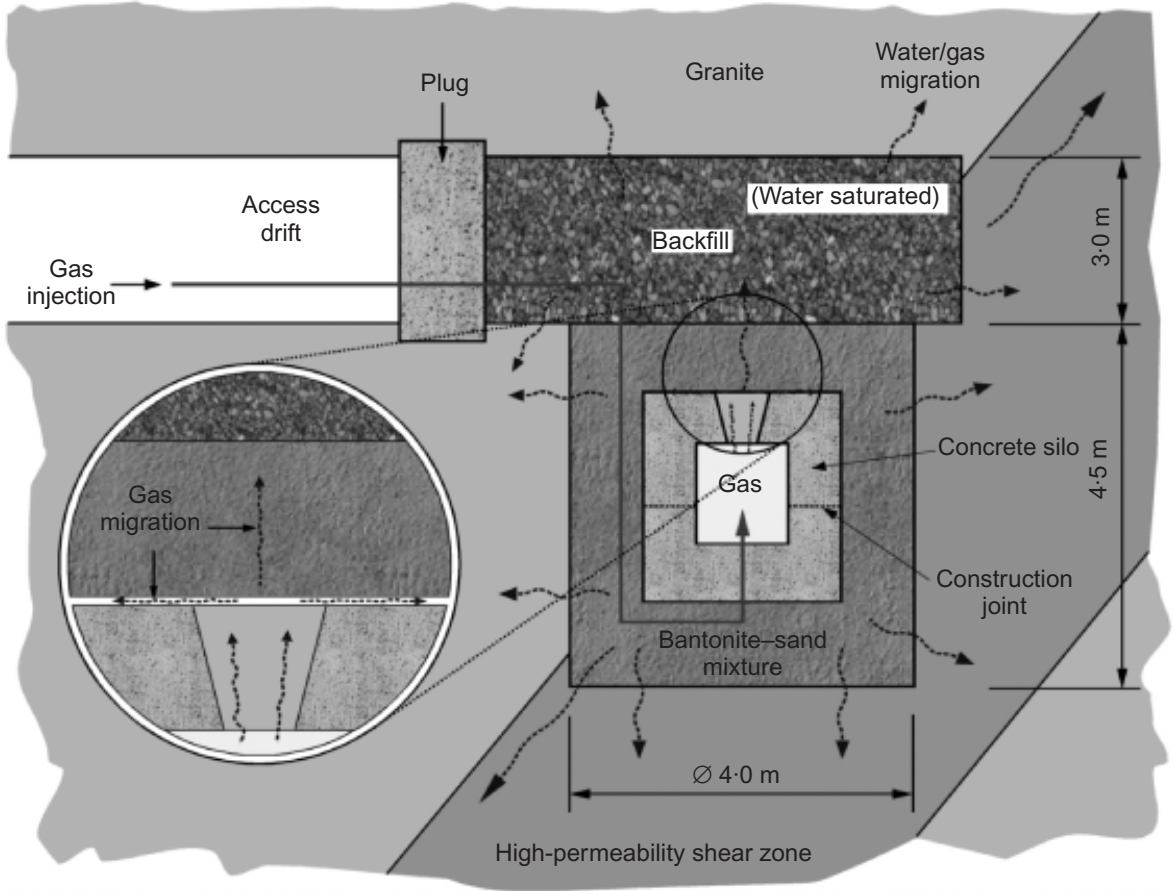

(a)

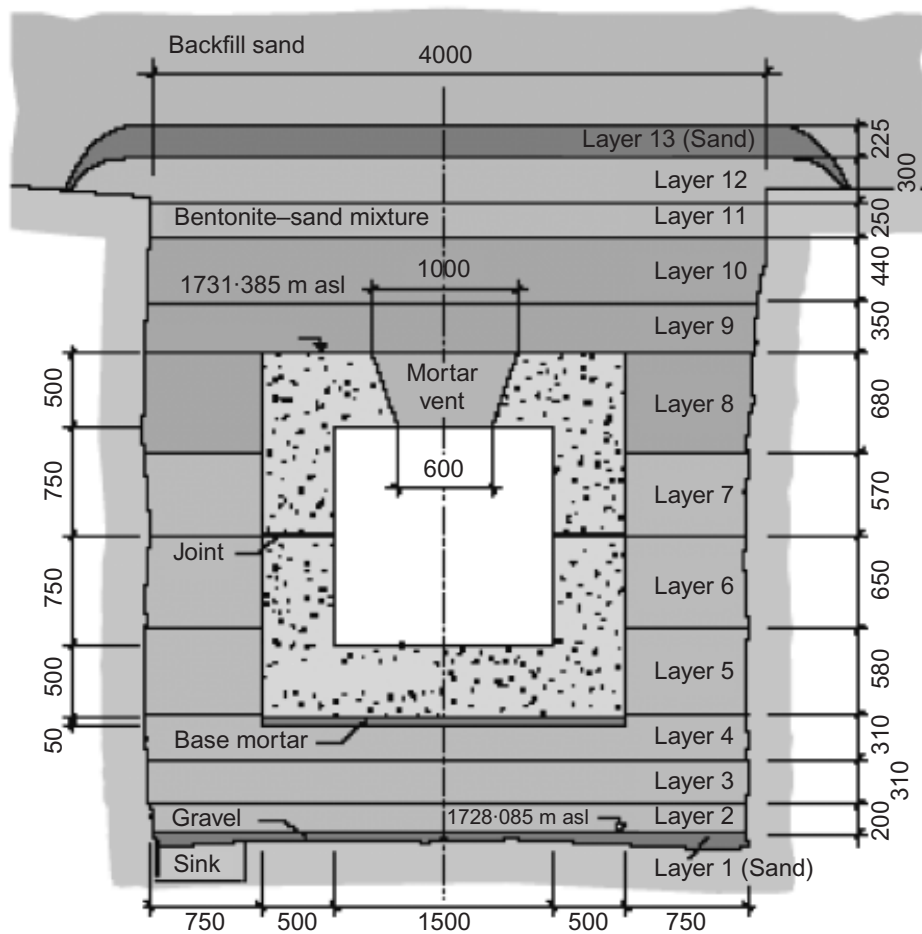

(b)

Fig. 7. (a) Proposed GMT experiment concept (dimensions in m). (b) Construction layers in GMT experiment (dimensions in $\mathrm{mm}$ ). Layers 8-10 were treated with lead nitrate in order to track gas flow paths (Schemes from NAGRA test design)

and gravel) and concrete seal built on the drift, which is gas and watertight. A high-permeability shear band in the granite host rock crosses the emplacement. However, all the simulations reported in the paper maintain cylindrical symmetry, although the effect of this pervious band was introduced in the analysis. During the initial part of the test water pressure was applied to the upper pervious chamber in order to saturate the EBS prior to gas injection tests.

The GMT test is described in various reports by NAGRA (e.g. Kickmaier et al., 2002; Lanyon \& Vomvoris, 2002).
The test has been simulated by means of a two-dimensional radially symmetric mesh with the symmetry axis parallel to the vertical axis of the concrete silo. The model includes different layers to incorporate the vertical and horizontal distribution of the elements of the EBS. Fig. 7 shows the compaction layers of the EBS barrier and their numbering.

Probably the most important feature of the calculations presented in this paper is that the interfaces are treated with special elements, just described, which contain an embedded fracture. An elasto-plastic model for unsaturated soils was 
used in this case as the reference constitutive model for the sand-bentonite mixture (the porous matrix). This permits modelling of water and gas flow with a high degree of complexity, which is necessary in view of the complex response shown in measurements. For example, Layer 1 has consistently shown a fast response, well correlated in time with the pressure at the water injection zone (upper chamber filled with sand/gravel), whereas Layers 2 to 6 remained at lower pressures and reacted more slowly. This indicates that there was a good connectivity between the upper chamber and the gravel at the bottom of the domain that bypasses the intermediate sand-bentonite layers. The 'mixed' elements described, located at the buffer/rock interface, developed this pervious connection in a natural way.

The physical model used for modelling of the GMT in situ test is based on a continuum approach for water, gas and momentum balance. Heterogeneity induced by different materials and different conditions of the same materials (for instance undamaged host rock and excavation-disturbed zone) is simulated by means of different properties defined for specific zones in the calculation domain. A number of different materials had to be defined. For instance, the interface elements at the boundary of the EBS keep the same initial properties as the sand-bentonite mixture, but at the same time they have the possibility of developing high permeability as extension takes place, owing to discrete path formation. Therefore permeability develops in an anisotropic manner, because the interfaces are directional in nature.

Figure 8 shows the discretised domain, the different EBS materials considered for model calculations, and the boundary conditions applied. Layers have been defined according to the construction stages (prior to water and gas injection phases, construction was simulated). Layers 2 to 12 are made of compacted sand-bentonite. Layer 1 is made of gravel, and it is in contact with the excavated bottom of the shaft. Layer 13 is made of sand, and is in contact with the upper boundary of the sand-bentonite backfill. The upper boundary of Layer 13 is in contact with the backfilling sand/ gravel that fills the upper cavity above the borehole. The inner and outer boundaries of the sand-bentonite mixture are in contact with the silo and the host rock respectively. However, each surface contact between the EBS and host rock is simulated by an interface element, as mentioned before. These elements contain an embedded discontinuity, and therefore their permeability may increase in the direction parallel to the contact. Seepage of air and water on the top and right boundaries means that water and air can only outflow. Additional numerical work, not reported here, in which interfaces at the contact between EBS and silo were considered, has been performed (Olivella \& Alonso, 2004). However, this did not contribute to any improvement of the results.

The sand-bentonite mixture compacted in Layers 8 to 10 was treated during compaction with lead nitrate, in order to visualise the gas flow paths subsequently by means of an injection of $\mathrm{SH}_{2}$ at some stage during the gas injection tests. $\left(\mathrm{SH}_{2}\right.$ and lead nitrate react, creating a black compoundlead sulphur - which it should be possible to identify during dismantling of the test.) However, the treated layers underwent a significant reduction in their swelling potential, and an increase in permeability, because the lead nitrate inhibited the bentonite's hydration properties. Therefore Layers 8, 9 and 10 were considered as a different material. In the remaining (and in Fig. 8) reference will be made to 'untreated' and 'treated' sand-bentonite mixture.

The model consists of 787 nodes and 748 elements (linear quadrilateral elements with four integration points) having a total vertical extent of $10.2 \mathrm{~m}$ and a radial extent of $4.5 \mathrm{~m}$.

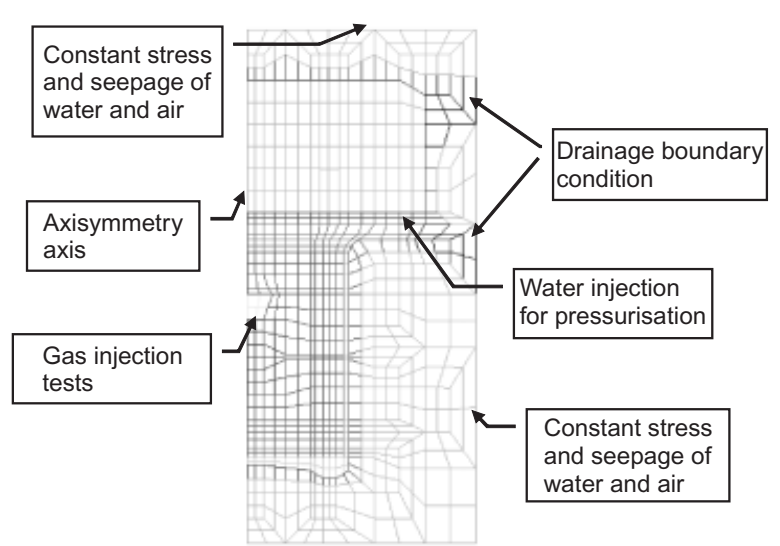

(a)

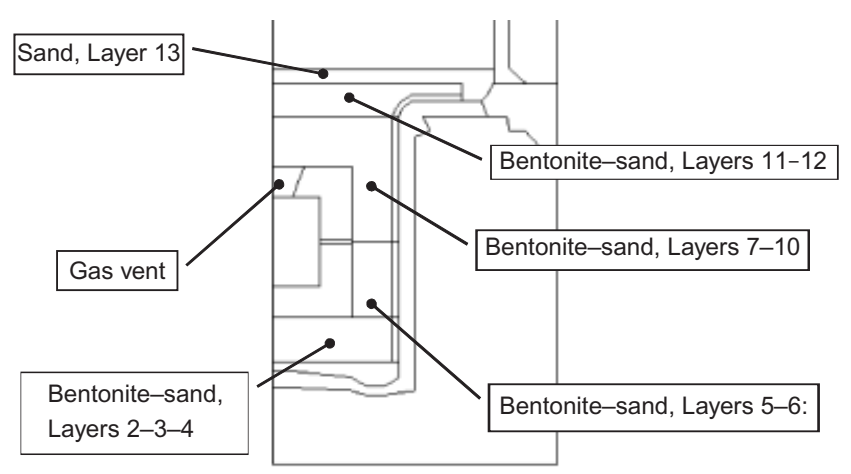

(c)

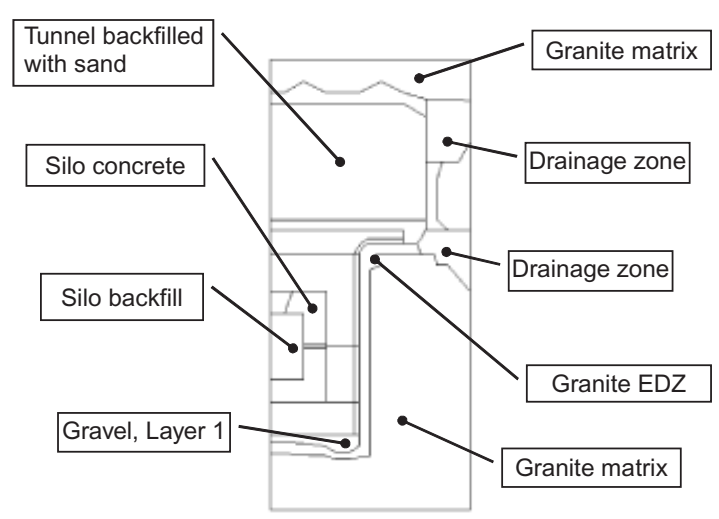

(b)

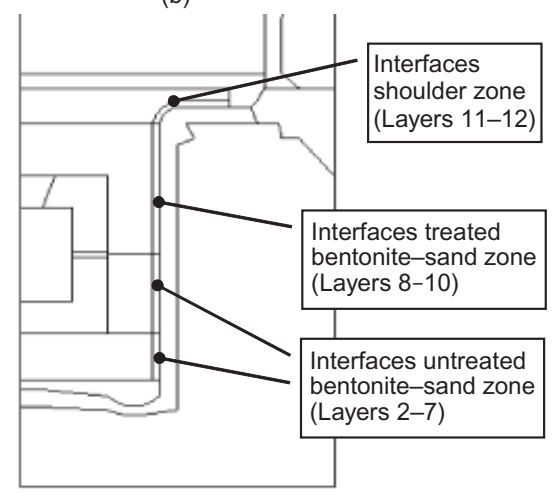

(d)

Fig. 8. Description of model for finite element calculations: (a) domain with mesh and boundary conditions; (b) domain with materials; (c) domain with materials (continued); (d) interfaces considered in the case presented (sand-bentonite with host rock) 
The hydraulic and mechanical properties for the different elements of the EBS and surrounding host rocks are taken from several reports (Lanyon, 2001; Lanyon et al., 2001a, 2001b; Marschall et al., 2001; Romero et al., 2002a, 2002b, 2003; Senger, 2002).

Figure 9 shows the results of some laboratory tests that were carried out at the UPC laboratory to characterise the EBS mixture. The retention curve was determined for drying and wetting conditions; however, an average curve was used for modelling purposes. The air entry value is less than $100 \mathrm{kPa}$, which is quite moderate, and a value of $P_{0}=$ $30 \mathrm{kPa}$ was considered in the calculations for the van Genuchten model.

A long-term suction-controlled oedometer test was important in characterising the mechanical behaviour under unsaturated conditions. For the EBS materials (treated and untreated), the elasto-plastic model described in Alonso et al. (1990) (the BBM model) has been considered. Some parameters could be found from a direct interpretation of the test results. For instance, the saturated elasto-plastic com- pressibility index was determined to be $\lambda(0)=0.049$ directly from the test in Fig. 9. However, most of the model parameters were approximated from a back-analysis of tests performed. Fig. 9(b) shows a comparison of the results of the suction-controlled oedometer test on untreated material and model calculations. Swelling of the sand-bentonite mixture is considered to be linearly dependent on suction: that is, the volumetric strain is defined as the product of the parameter $a_{\mathrm{s}}$ and the suction change.

One additional important result of the oedometer test shown in Fig. 9(b) is the determination of the swelling pressure. The first imposed path on the compacted specimen (path AB: swelling under constant volume) leads to an increase in the confining vertical stress, which reached a maximum of $100 \mathrm{kPa}$. Therefore the $(20 / 80$ mixture in weight) sand-bentonite mixture has a low swelling pressure if compared with other buffer materials considered for nuclear waste isolation.

The complete set of hydraulic and mechanical parameters for the EBS and remaining materials is summarised in Table

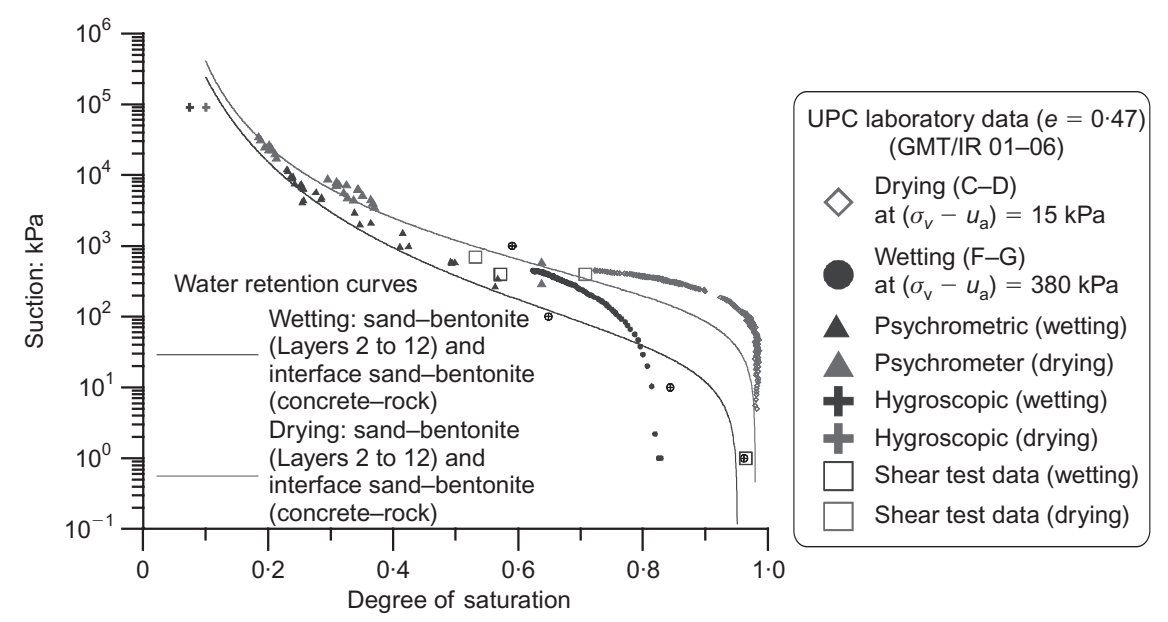

(a)

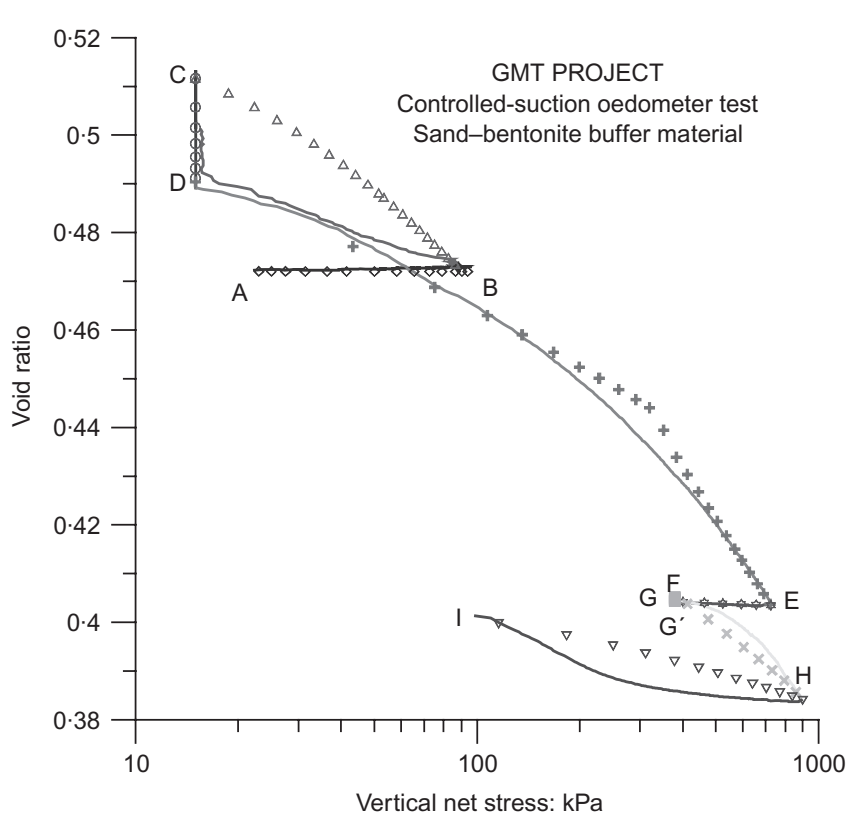

(b)
A-B: isochoric

wetting

B-C: Loading at

constant suction

C-D: drying at

constant stress

D-E: loading at

constant suction

E-F: unloading at

constant suction

F-G: wetting at

constant stress

G-H: loading at

constant suction

$\mathrm{H}-\mathrm{I}$ : unloading at

constant suction

Fig. 9. Laboratory tests performed at UPC soil mechanics laboratory; (a) water-retention curves of sand-bentonite mixture; (b) suction-controlled oedometric test on compacted sand-bentonite specimen. Results of test simulation using an elasto-plastic model also shown 
3 (bulk materials) and Table 4 (for specific properties of interfaces). It can be observed that the granite has a low intrinsic permeability $\left(k=6 \times 10^{-19} \mathrm{~m}^{2}\right)$ and high stiffness $(E=30000 \mathrm{MPa})$. The rock permeability is increased at the EDZ (excavation disturbed zone) annular material around the excavations $\left(k=5 \times 10^{-17} \mathrm{~m}^{2}\right)$, and also in a drainage zone $\left(k=1 \times 10^{-16} \mathrm{~m}^{2}\right)$ assumed in the rock in order to approximate the shear zone crossing the test area.

For the liquid and gas relative permeabilities a generalised power law (GPL) (equation (7)) was adopted for all materials. The exponent of the degree of saturation is referred to as $n_{1}$ or $n_{\mathrm{g}}$ respectively, for liquid and gas.

According to the model presented in this paper, the interfaces are similar in hydro-mechanical behaviour to the sand-bentonite mixture, but a preferential path may develop, depending on the deformations taking place. Fig. 8(d) shows the location of the interface elements considered in the simulation.

There are a number of additional assumptions considered in the calculations. No access tunnel (which is actually sealed with a concrete plug) is simulated. The entire problem has been solved under isothermal conditions at a constant temperature of $20^{\circ} \mathrm{C}$. Gas dissolved in the liquid phase is permitted. Its concentration is computed through Henry's law.

The definition of testing steps, for calculation purposes, has been performed according to what has been actually done in the field. The test sequence has been described in detail in several reports (Lanyon, 2001; Lanyon et al., 2001a, 2001b; Kickmaier et al., 2002; Lanyon \& Vomvoris, 2002; Trick, 2002, 2003). Simulation of the construction of different layers is important, because this is a way to determine the stress-pressure conditions before fluid injection. After construction of the different materials, water injection and pressurisation have been simulated. Finally, the gas injection tests RGI1 to RGI4 were run, according to the planned activities. During the performance of gas injection tests water was injected at a constant flow rate.

Actual stresses in the rock are probably not in accordance with the depth of the testing gallery, because in the vicinity of the test there are other access and observation drifts that contribute to overall stress relaxation. For this reason, an initial stress state of $1 \mathrm{MPa}$ is considered for the rock, since only a small portion of granite is considered. A normal stress of $1 \mathrm{MPa}$ is also applied at the outer boundary to satisfy equilibrium. Since the actual granite rock is a massive stiff and elastic material, the role of the initial stress state in the rock is minor in this case.

Cavern pressurisation was an important stage in GMT because high pressures have been achieved, and the surrounding environment has a relatively high drainage capacity. The pressurisation was achieved by means of a radial water flow rate injection at Layer 12. During water injection, saturation of different zones took place at early stages. At a later stage water pressure increased, and a water flow under quasi-steady-state conditions was established. Under these conditions, and according to in situ measurements, water outflow was taking place mainly through the high-permeability shear zone.

The pervious shear zone is characterised by a special boundary condition to permit drainage of water. It is expressed as an outflow rate (per unit area of boundary) given by

$$
Q_{\text {outflow }}=\left\{\begin{array}{l}
\gamma(t)\left(p_{1}-p_{1}^{0}\right) \text { for } p_{1}>p_{1}^{0} \\
0 \text { otherwise }
\end{array}\right.
$$

where $p_{1}, p_{1}^{0}$ are the calculated and imposed liquid pressures at the boundary, and $\gamma(t)$ is a function of time, which was

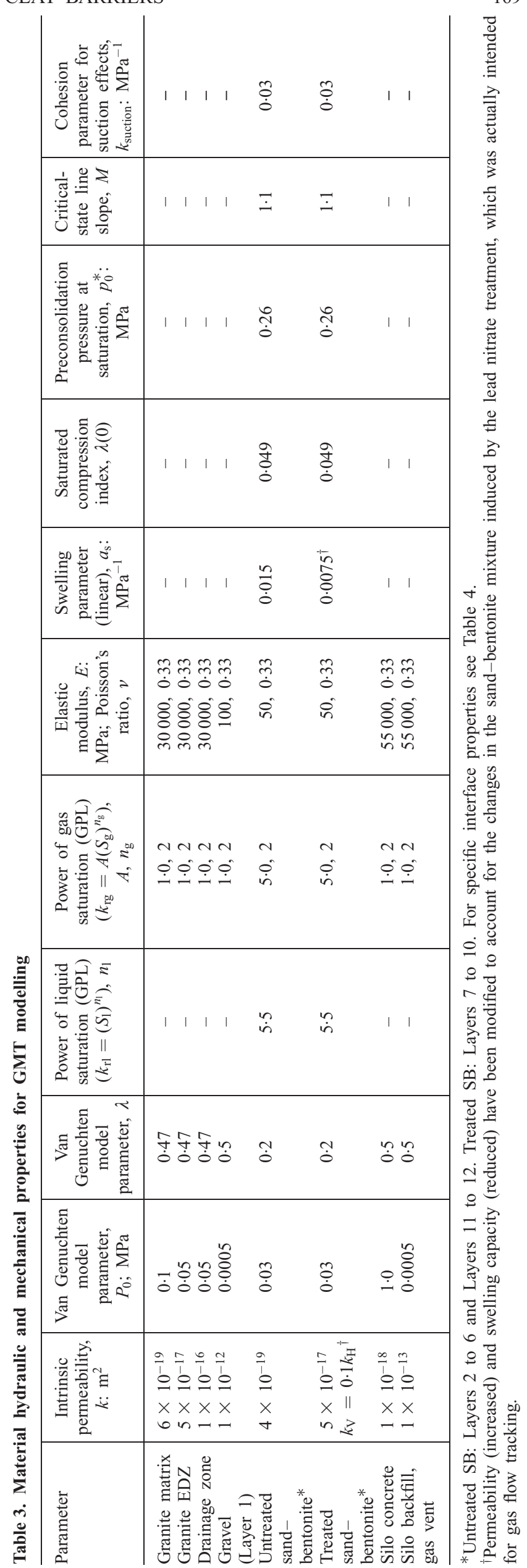


Table 4. Interface permeability and capillary pressure for GMT modelling

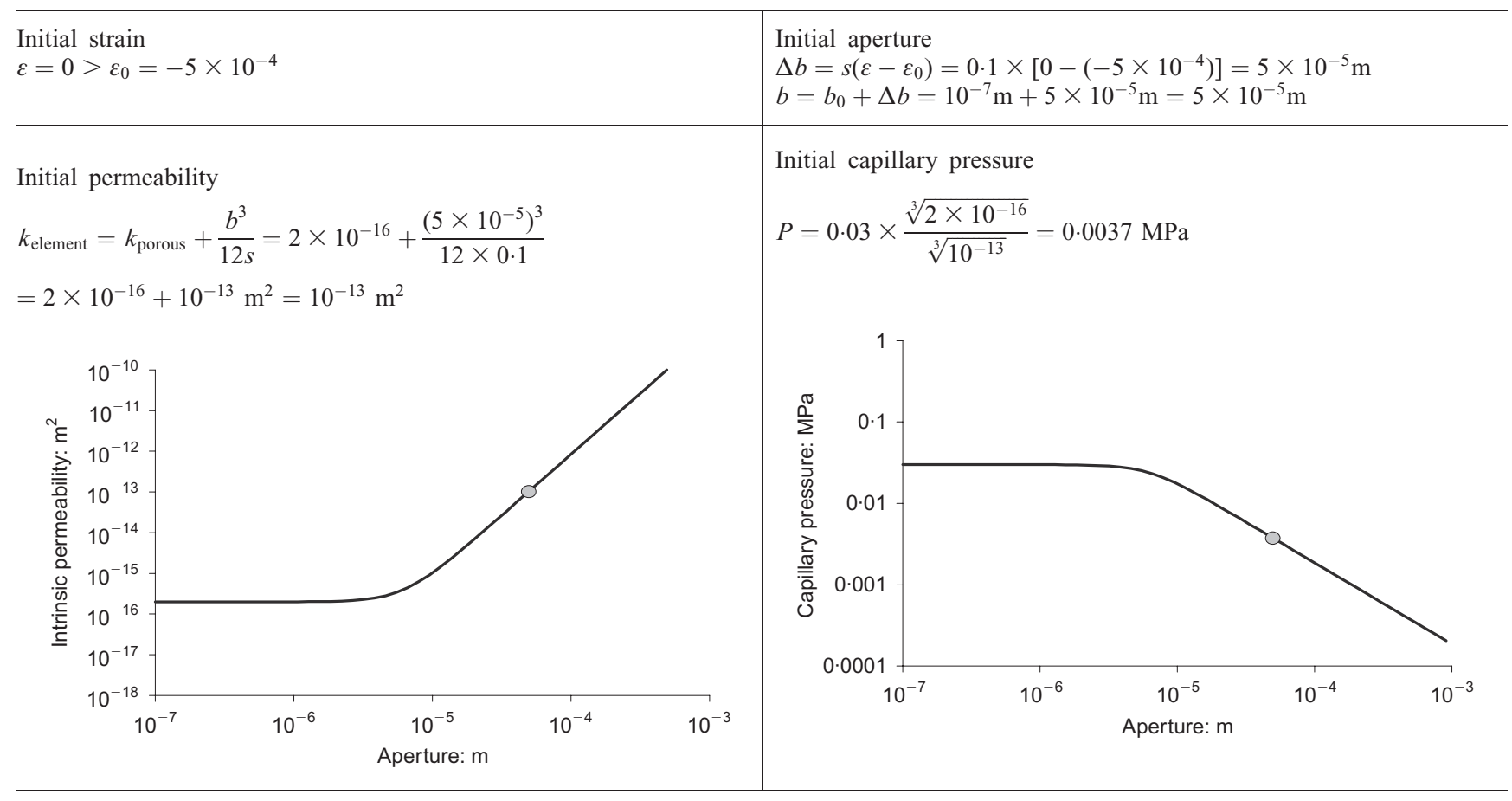

calibrated in order to represent the observed permeability reduction of the host rock as the test progressed. This boundary condition, variable with time, has been applied only on the boundary in contact with the material indicated as 'Drainage zone'. The value of $\gamma(t)$ is higher in this zone than in the remaining parts of the boundary, where seepage can also take place.

Figure 10 shows the water flow rate at the injection point and the protocol during the gas pressure tests RGI1, RGI2, RGI3 and RGI4. Water flow rate injected for pressurisation was considered in the model with the actual values used in situ. However, the injection pressure was limited to $0.57 \mathrm{MPa}$, and this implied a smaller amount of water injected. It is clear that the model does not completely capture the reality. Probably, in reality, there were dead volumes in the test that had to be filled, and this results in more time required to reach steady flow (as shown in Fig. 10). In the case of gas, the actual flow rate of gas injection tests was introduced in calculations without experiencing numerical problems. Gas injection was imposed inside the silo, just below the gas vent element that closes the silo in its central upper part.

\section{Results and discussion}

The results in terms of pressures, volumetric water content and stresses are presented for the analysis performed, together with the measurement of these variables. Additionally, calculated permeability evolution is shown for the interfaces. Their initial state is defined in Table 4.

Calculated liquid and gas pressures are shown in Fig. 11, where they are compared with measurements in a number of piezometers located in these layers. Depending on the permeability of each layer, the response is different. Layer 11 is made of untreated sand-bentonite, and its low permeability implies a slow response of pressures. In contrast, Layer 9 was made of treated sand-bentonite, and its larger permeability implies a much faster response. Finally, Layer 3-4 and Layer 2, which are also made of untreated sandbentonite, show a slow response. However, Layer 2 is close to Layer 1 (gravel), which had good connection with the injection of water, and therefore Layer 2 also shows the effects of the fast pressure variations in Layer 1.

Volumetric water content is compared in Fig. 12 for Layers 8 and 11. Whereas for Layer 8 full saturation is achieved during pressurisation of the test, for Layer 11 the response is slower. The gas injection tests are reflected in the curves for Layer 8, but no effect is observed for Layer 11. The results for volumetric water content in Layer 8 and Layer 11 are a consequence of the different properties that were induced by the lead nitrate treatment.

Stresses were also measured and calculated for the GMT test in order to investigate coupled hydro-mechanical effects. The calculated and measured stresses are plotted in Fig. 13 for Layers 8, 6-7 and 3. The sensor in Layer 3 is located below the silo. An underprediction of the calculated vertical stress is observed, while measurements respond simultaneously with the pressurisation. Horizontal stresses have been calculated and measured at a point between Layers 6 and 7. For Layer 8, the vertical stress is captured well by the model. In general, total stresses are controlled by the pressurisation of the upper cavern. Stress measurements (and calculations) show the effect of gas injection tests. Total stress response induced by pore pressure variations is an indication of small volumetric strains, which are prevented by the confining host rock.

The measured pore pressures in the test can be simulated in a realistic way if the interfaces are included. These interfaces undergo large changes of permeability, which are motivated by several coupled processes. It is convenient to interpret these phenomena in terms of effective stress (Fig. 14). Total stress minus pore pressure (the maximum of either gas or liquid pressure) is the definition of effective stress adopted in the model for the sand-bentonite mixture. Effective stress controls the opening or closure of discontinuities (interfaces between sand-bentonite and host rock). As pore pressure increases at the interface and the buffer pore pressure remains unchanged, the interface opens because the buffer compresses. This is the situation if the sand-bentonite buffer remains unsaturated, which is the case for the untreated sand-bentonite mixture during the initial stages of the test. If the buffer is more pervious (treated sand- 

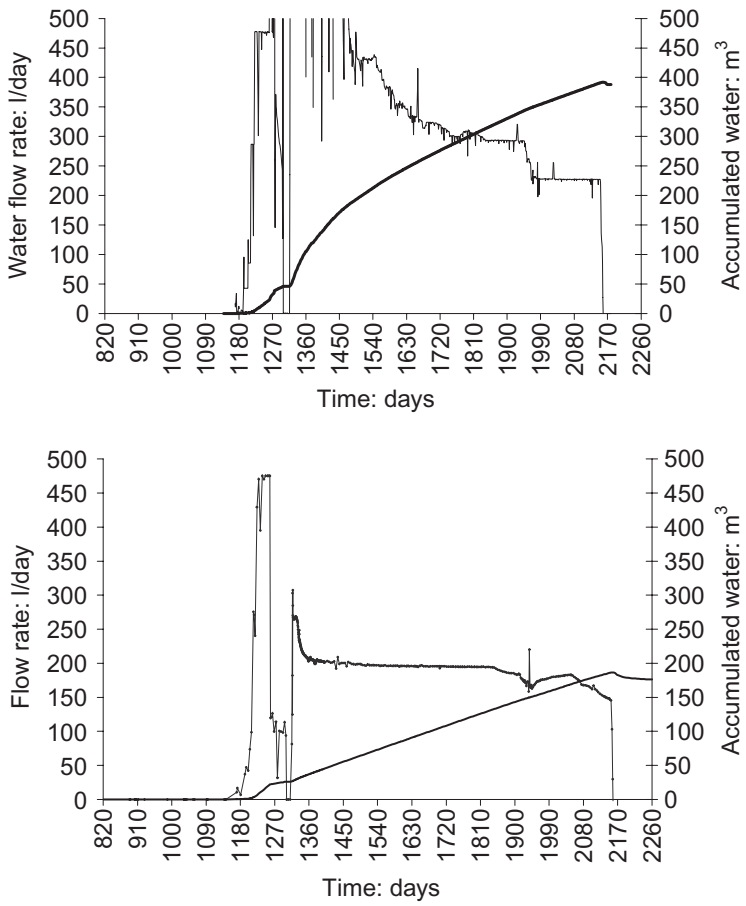

(a)

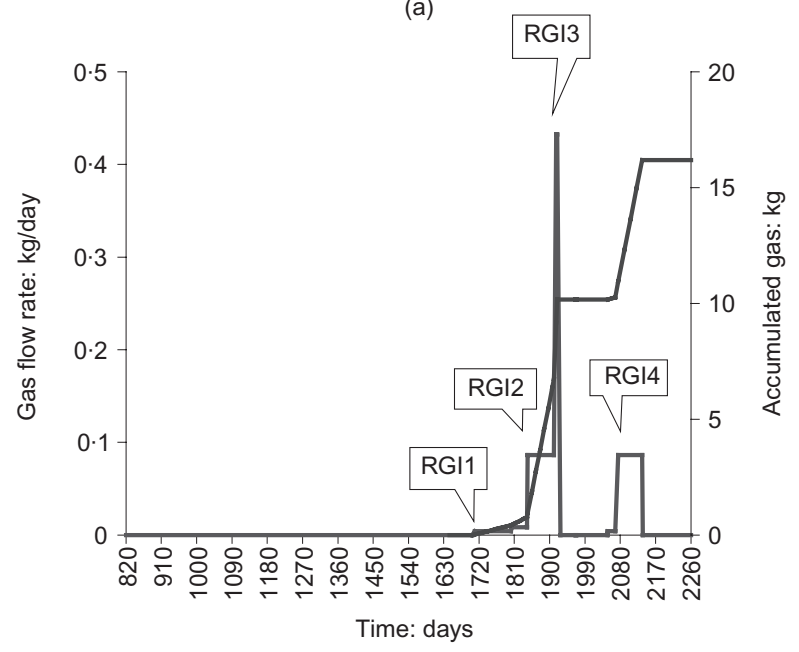

(b)

Fig. 10. (a) Variation of water flow rate for cavern pressurisation (upper figure, measured; lower figure, calculated). Water is injected through a peripheral circular pipe in sand Layer 12. (b) Variation of gas flow rate for gas injection tests RGI1, RGI2, RGI3 and RGI4. This gas flow rate is injected inside the silo and escapes from it through the so-called 'gas-vent'

bentonite), the fluid flow equilibrates the pressure more rapidly (and eventually becomes saturated). In this case, an increase in water pressure at interfaces bounding a saturated buffer does not change the effective stresses of the sandbentonite. Then it is more difficult for the interfaces to open. The permeability of the buffer is therefore a controlling factor for the behaviour of the interfaces in this test.

The evolution of permeability at interfaces is represented in Fig. 15 for the three characteristic zones of the test where interfaces have been considered. The three zones are

(a) Shoulder zone (Layers 11-12). This zone connects the upper cavern and the EBS. During the tests, water and gas flow through this zone takes place from the cavern to the EBS, and vice versa. This is a geometrically complex zone owing to the different excavation diameters. The sand-bentonite in Layers 11 and 12 was untreated sand-bentonite.

(b) Treated sand-bentonite (Layers 8-9-10). This zone is roughly in front of the upper part of the silo, and therefore it is located near the gas injection point. The sand-bentonite was treated with lead nitrate, as mentioned before, to try to visualise the gas flow path, but this treatment induced changes in permeability and swelling potential.

(c) Untreated sand-bentonite (Layers 2-3-4-5-6-7). This zone is roughly in front of the lower part of the silo. The material in Layers 2 to 7 was not treated with lead nitrate, since it was not expected that the gas would flow towards this lower zone.

For the three zones, the interfaces simulate contact of sandbentonite and host rock. As indicated in Table 4, the initial permeability is high, to represent the initial state after construction. The different construction, pressurisation and gas injection processes motivate large changes in permeability (Fig. 15). The following comments discuss these changes.

The shoulder zone is characterised by a reduction of permeability during construction. Permeability increases at some points during cavern pressurisation, but tends to reduce again. The gas injection tests (gas is injected from the silo, and tends to escape through the upper cavern) also induce some permeability enhancements.

The interfaces that model the contact between treated sand-bentonite (layers from 8 to 10) and host rock show a different permeability evolution. Cavern pressurisation produces moderate increments of permeability, which tend to reduce as saturation progresses. This is due to moderate swelling effects and pore pressure equilibration in the treated sand-bentonite.

The interfaces that simulate the contact between untreated sand-bentonite (Layers from 2 to 7) and host rock show a very high increment of permeability during the cavern pressurisation phase. The interfaces tend to close, but very slowly owing to swelling and pore pressure equilibration. The different response of the interface in the untreated and treated sand-bentonite zones is motivated by the lower permeability of the original material compared with the treated material.

It can be observed that, in the case of a rapid pressurisation, the interfaces open more if the permeability of the buffer is lower. The rate of pressurisation is therefore a crucial aspect in controlling the subsequent behaviour of the entire test. The pressurisation is due either to water injection or to gas injection. The GMT test had two main events that produce interface opening: the water injection in Layer 12 for upper cavern pressurisation; and the gas injection in the silo to carry out the RGI tests. Fig. 16 shows the distribution of water and gas fluxes in the test during the water pressurisation phase, and during a gas injection test. These events cause irreversible deformations in the buffer and at the interfaces, which are also shown in Fig. 16.

\section{CONCLUSIONS}

Using a few simple concepts of fracture development, and the associated two-phase flow phenomena along discontinuities, a continuum model capable of simulating flow in a fractured porous medium has been developed. The calculation procedure is developed within the framework of a hydro-mechanical model for geological media that is based on a coupled flow-deformation formulation and a versatile numerical program (CODE_BRIGHT). A realistic represen- 


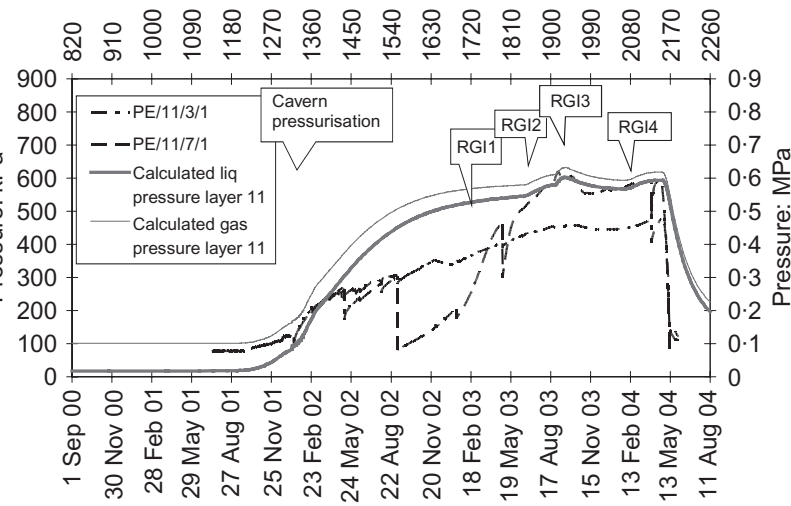

(a)

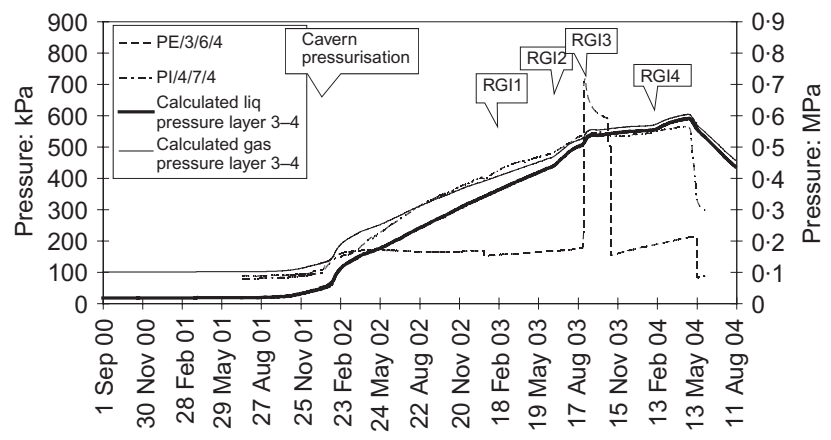

(c)

Fig. 11. Evolution of liquid and gas pressures compared with measurements at sensors: (a) Layer 11 (untreated); (b) Layer 9 (treated); (c) Layers 3-4 (untreated); (d) Layer 2 (untreated)

days

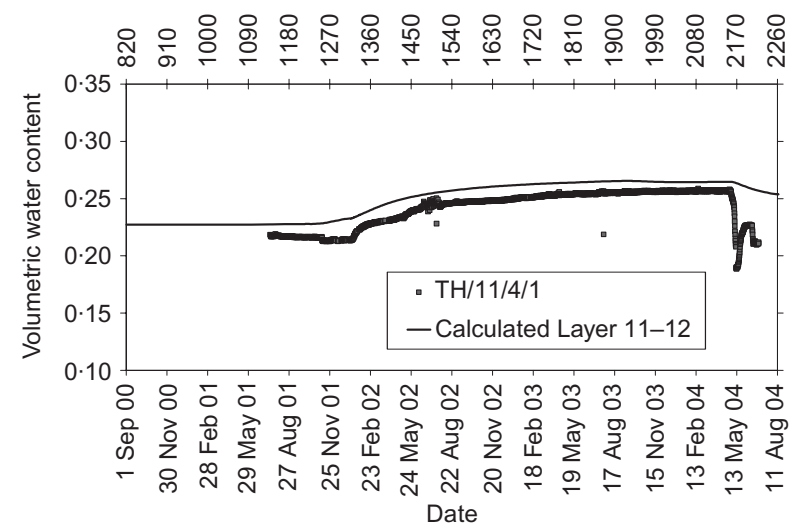

(a)

days

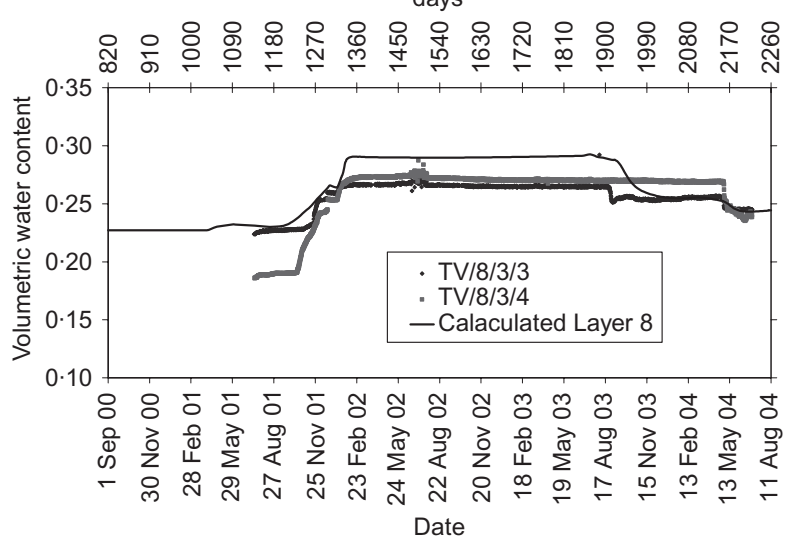

(b)

Fig. 12. Evolution of water content compared with measurements at sensors: (a) Layer 11 (untreated sand-bentonite); (b) Layer 8 (treated sand-bentonite)

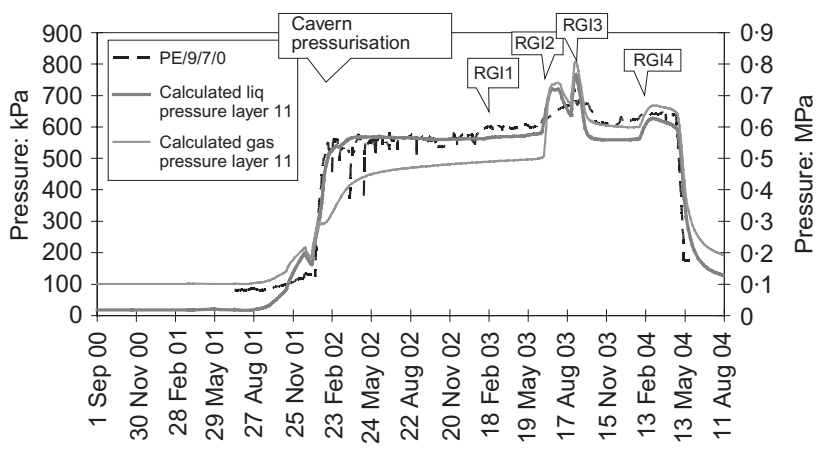

(b)

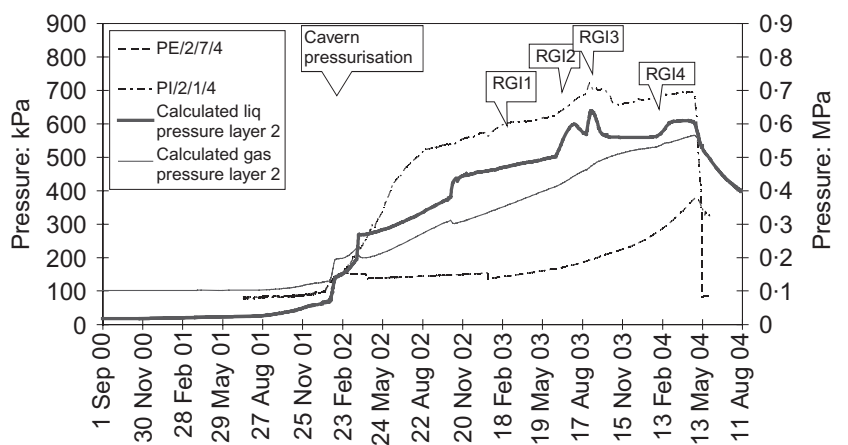

(d)

tation of irreversible fracture opening requires an elastoplastic constitutive model for the soil or rock skeleton. Fracture opening is characterised by a threshold strain parameter that marks the opening of the fracture. Computer simulations, inspired in tests conducted to study gas flow through different geological materials, have been presented. The analyses show the sensitivity of results to the mechanical parameters of the interface. It is shown that the model reproduces in a natural way the peak discharge phenomena and peak gas pressure often reported in experiments. The model includes two mechanisms that are generally present in a given experiment: two-phase flow, and concentrated flow through fractures.

The model developed offers good capabilities to solve, in a realistic and relatively simple manner, the complex phenomena of gas flow through fractured or potentially fractured rock. In order to show the capabilities of the model, two examples (a laboratory and a field test) have been presented. The simulation of gas pulse tests through a specimen of Opalinus clay shale highlights the sudden increase in gas permeability induced by sample shearing, and the ability of the initially unsaturated rock to seal the preferential gas paths because of matrix swelling.

The large GMT demonstration test- a complex experiment because of its geometry, the number of different materials, and the involved testing protocol-provided a good opportunity to validate the predictive capabilities of the developed model. It is shown that model calculations reproduce in a satisfactory manner the evolution of the main variables recorded during the test: fluid pressures at different points within the sand-bentonite buffer; changes in water content; and total stress against several interfaces. A key aspect in reproducing the entire history of test results is the ability of the interfaces introduced in the model to modify their permeability by several orders of magnitude as a 


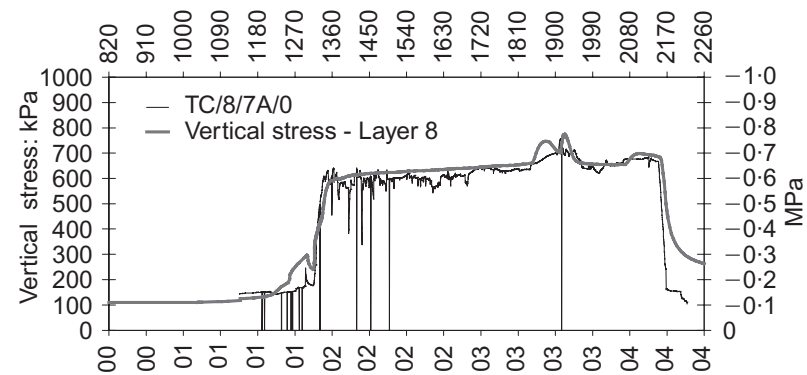

8

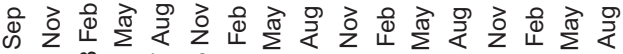

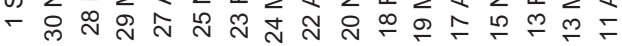
Date

(a)

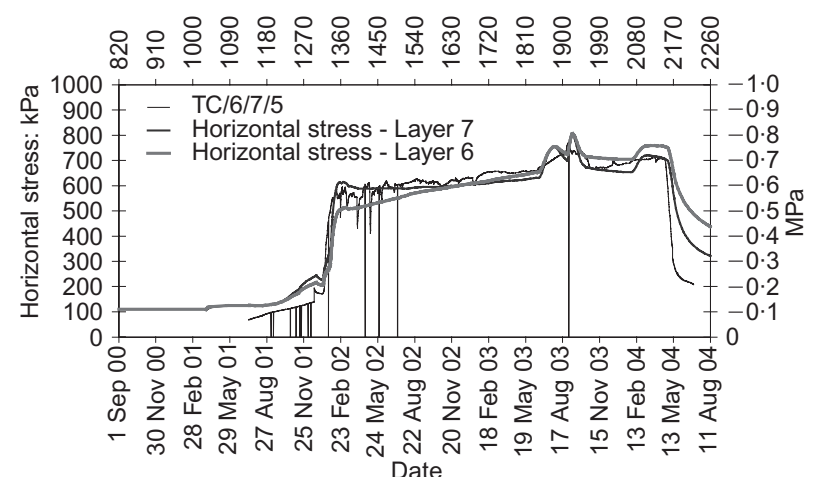

(b)

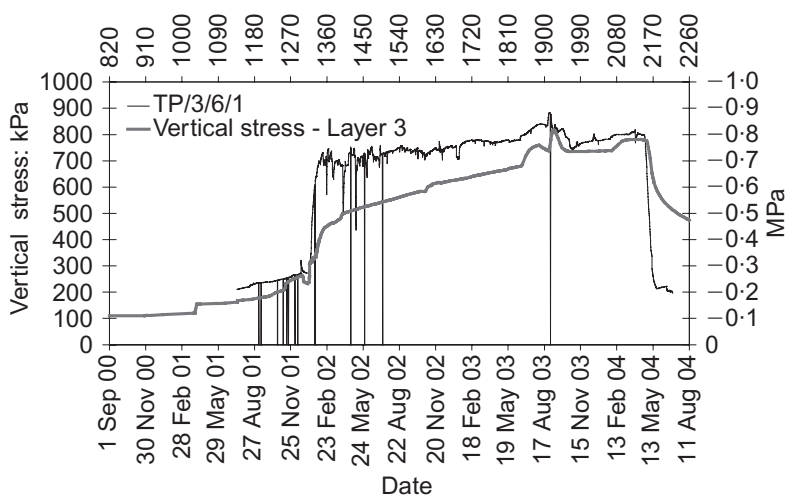

(c)

Fig. 13. Evolution of stresses compared with measurements at sensors (TC or TP): (a) Layer 8 (treated sand-bentonite); (b) Layers 6-7 (untreated sand-bentonite); (c) Layer 3 (untreated sand-bentonite)

response to stress and strain changes. Interpretation of the test requires a due consideration to be paid to the behaviour of saturated and unsaturated buffer zones. It was found that the rate of water pressurisation and gas injection controls the magnitude of interface opening, which in turn dictates the evolution of pore pressures and stresses within the buffer. The model also produced an overall physical interpretation of the gas flow during injection tests. Gas left the inner silo through the upper vent and migrated radially along the contact between the top of the silo and the compacted sand-bentonite. It then crossed the compacted layers of the buffer at the level of Layers 9-10 and went into the rock/ buffer interfaces. The steady flow of water out of the cavern conducted the gas towards the upper and more pervious rock shearing zone, where it flowed out in the gas phase as well as dissolving in the outflow current of liquid water.

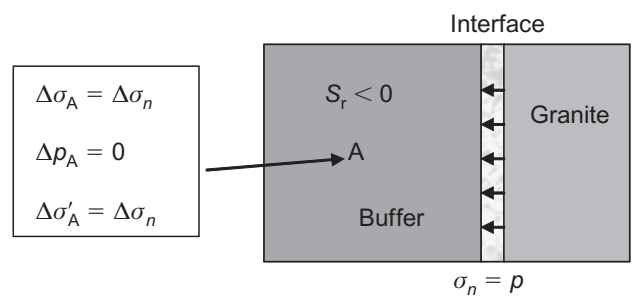

Impervious buffer:

Interface: $\sigma_{n}^{\prime} \approx 0 \Rightarrow \sigma_{n} \approx p \Rightarrow$ Extension Buffer: $\Delta p_{\mathrm{A}} \approx 0 \Rightarrow\left(\Delta \sigma_{n}^{\prime}\right)_{\mathrm{A}} \approx\left(\Delta \sigma_{n}\right)_{\mathrm{A}} \Rightarrow$ Compression

Pervious buffer:

$$
\begin{gathered}
\text { Interface: } \Delta \sigma_{n}^{\prime} \approx 0 \Rightarrow \sigma_{n} \approx \Delta p \Rightarrow \text { No deformation } \\
\text { Buffer: } \Delta p_{\mathrm{A}} \approx\left(\Delta \sigma_{n}\right)_{\mathrm{A}} \Rightarrow\left(\Delta \sigma_{n}^{\prime}\right)_{\mathrm{A}} \approx 0 \Rightarrow \text { No deformation }
\end{gathered}
$$

Fig. 14. Interface opening due to pore pressure increase. Buffer remains unsaturated owing to its low permeability. Unsaturated buffer is compressible; permits interface to open as extension deformations take place

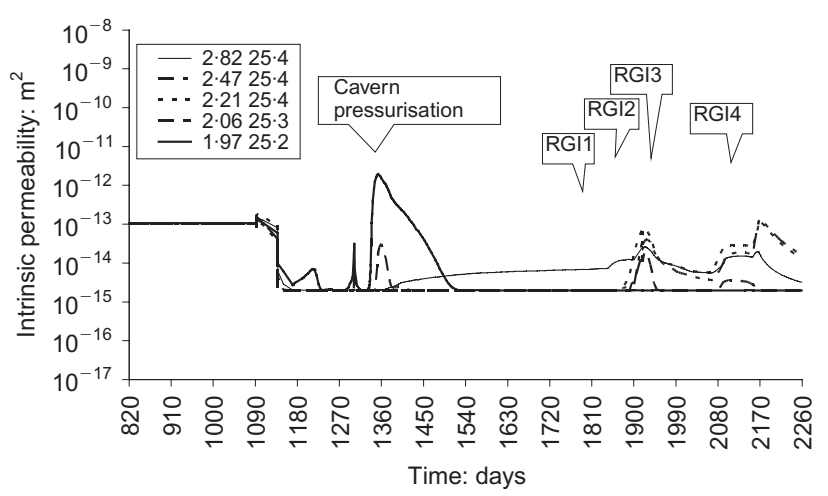

(a)

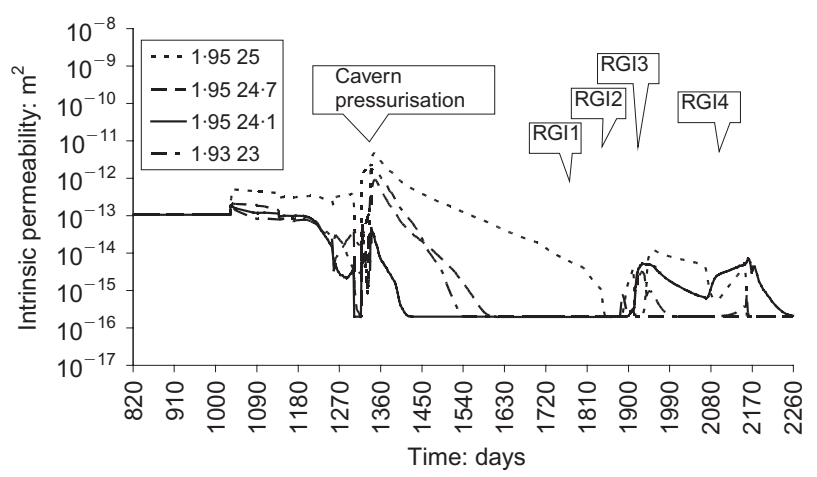

(b)

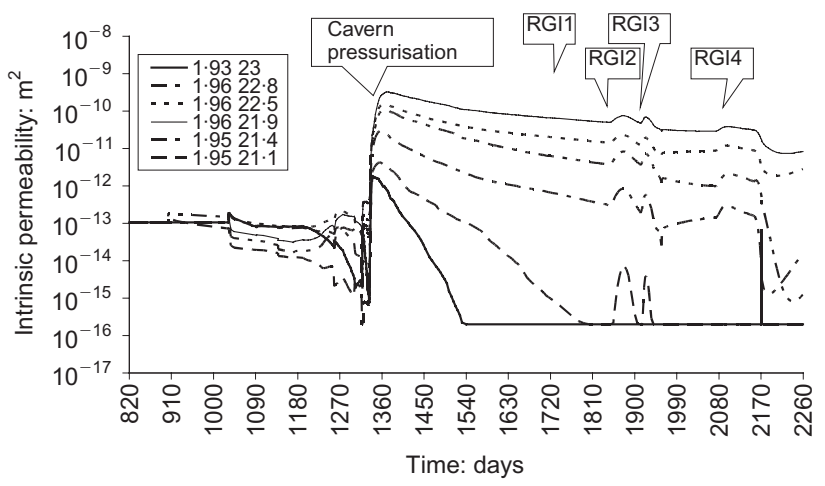

(c)

Fig. 15. Calculated evolution of intrinsic permeability at interface elements between sand-bentonite and host rock: (a) shoulder zone (Layers 11-12); (b) treated sand-bentonite (Layers 8-9-10); (c) untreated sand-bentonite (Layers 2-3-45-6-7) 

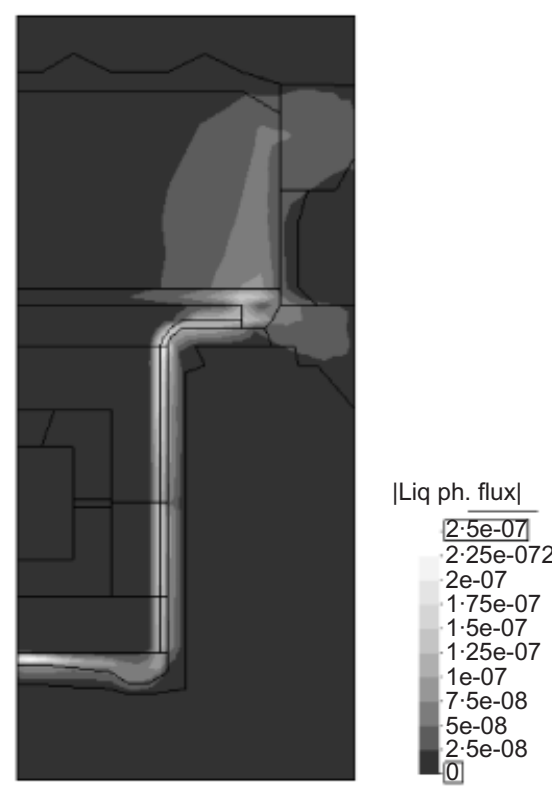

(a)

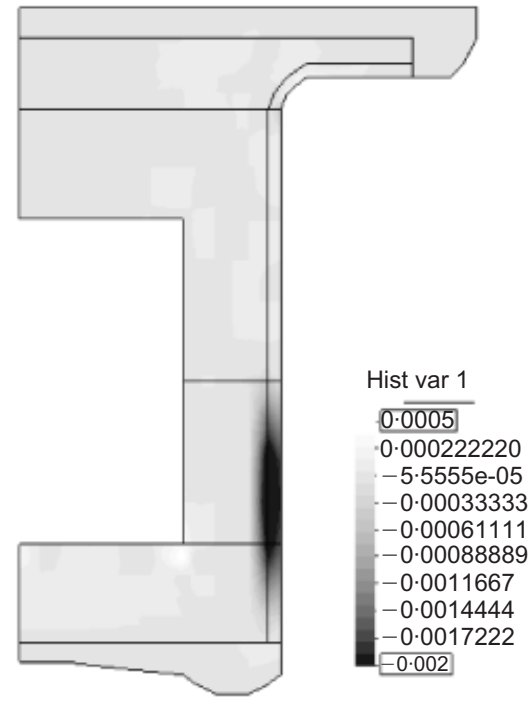

(c)

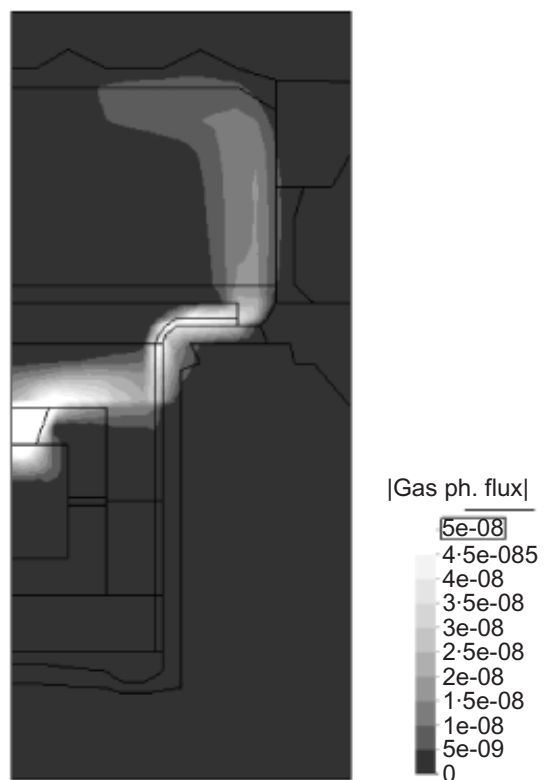

(b)

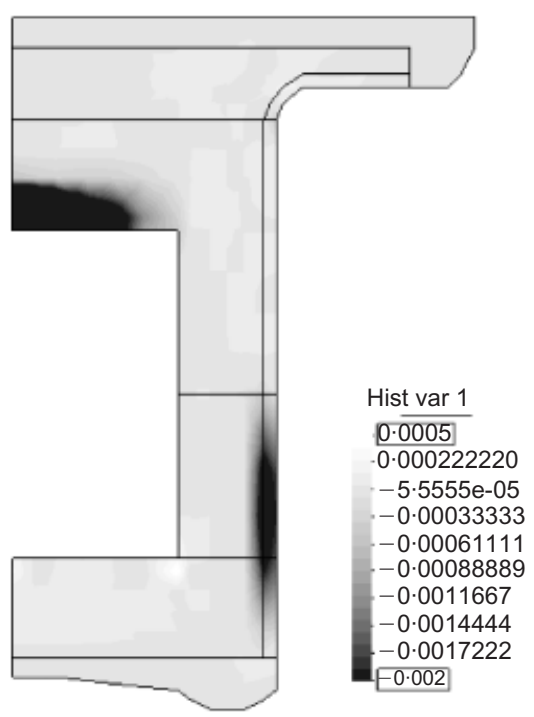

(d)

Fig. 16. Contour fields of (a) water fluxes $(\mathrm{m} / \mathrm{s})$ during pressurisation (a), (b) gas fluxes $(\mathrm{m} / \mathrm{s})$ during gas injection tests; volumetric irreversible deformations in buffer during (c) pressurisation, (d) gas injection

\section{ACKNOWLEDGEMENTS}

The authors would like to acknowledge NAGRA (Switzerland), RWMC, JNC, Obayashi Corporation (Japan) and the Monterri Consortium for funding this investigation through several research contracts.

Special thanks are given to the following individuals for their support throughout the research reported in this paper: P. Marschall, S. Vomvoris and W. Kickmaier (NAGRA); Bill Lanyon (Fracture Systems Ltd, UK); H. Asano, T. Shimura, A. Fujiwara, K. Tanai, S. Yamamoto, K. Ando, T. Tanaka (RWMC, JNC, Obayashi Corporation).

\section{APPENDIX. COUPLED THM FORMULATION FOR GAS FLOW}

The balance equations required for the solution of the problems discussed in this paper are presented. Olivella et al. (1994) described the governing equations for non-isothermal multiphase flow of water and gas through porous deformable media. A general derivation is given there, and only a description of the specific formulation for gas flow is presented in this Appendix.

The mass balance of solid present in the medium is written as

$$
\frac{\partial}{\partial t}\left[\rho_{\mathrm{s}}(1-\phi)\right]+\nabla \cdot\left(\mathbf{j}_{\mathrm{s}}\right)=0
$$

where $\rho_{\mathrm{s}}$ is the mass of solid per unit volume of solid, and $\mathbf{j}_{\mathrm{s}}$ is the flux of solid. From this equation, an expression for porosity variation can be obtained if the flux of solid is written as the velocity of the solid multiplied by the volumetric fraction occupied by the solid phase and the density, that is, $\mathbf{j}_{\mathrm{s}}=\rho_{s}(1-\phi)(\mathrm{du} / \mathrm{d} t)$ :

$$
\frac{D_{\mathrm{s}} \phi}{D t}=\frac{1-\phi}{\rho_{\mathrm{s}}} \frac{D_{\mathrm{s}} \rho_{\mathrm{s}}}{D t}+(1-\phi) \nabla \cdot \frac{\mathrm{du}}{\mathrm{d} t}
$$

The material derivative with respect to the solid is defined as

$$
\frac{D_{\mathrm{s}}(\bullet)}{D t}=\frac{\partial}{\partial t}+\frac{\mathrm{d} \mathbf{u}}{\mathrm{d} t} \cdot \nabla(\bullet)
$$

Equation (15) expresses the variation of porosity caused by volumetric deformation and solid density variations. 
Two phases are considered: gas and liquid. The total mass balance of a component $i$ present in each phase (for instance a gas that may dissolve, or water that may evaporate) is expressed as

$$
\frac{\partial}{\partial t}\left(\omega_{1}^{i} \rho_{1} S_{1} \phi+\omega_{\mathrm{g}}^{i} \rho_{\mathrm{g}} S_{\mathrm{g}} \phi\right)+\nabla \cdot\left(\mathbf{j}_{1}^{i}+\mathbf{j}_{\mathrm{g}}^{i}\right)=f^{i}
$$

where $S_{1}, S_{\mathrm{g}}$ are the phase degrees of saturation; $\omega_{1}^{i}, \omega_{\mathrm{g}}^{i}$ are the mass fractions of the component $i$ in each phase; $\rho_{\mathrm{l}}, \rho_{\mathrm{g}}$ are the phase densities; $\mathbf{j}_{1}^{i}, \mathbf{j}_{\mathrm{g}}^{i}$ are the mass fluxes of the component $i$ in each phase; and $f^{i}$ is an external supply of mass of component $i$. In this formulation the components are the water and the generated gas (for instance hydrogen, in the case of corrosion). The mass flux of components is a combination of: a non-advective flux (diffusion + dispersion), written as $\mathbf{i}_{1}^{i}, \mathbf{i}_{\mathrm{g}}^{i}$, the advective Darcy flux, written as $\mathbf{q}_{1}$, $\mathbf{q}_{\mathrm{g}}$; and another advective term caused by the solid motion, which is proportional to the solid velocity $\mathrm{d} \mathbf{u} / \mathrm{d} t$, and given by

$$
\begin{aligned}
& \frac{\partial}{\partial t}\left(\omega_{1}^{i} \rho_{\mathrm{l}} S_{\mathrm{l}} \phi+\omega_{\mathrm{g}}^{i} \rho_{\mathrm{g}} S_{\mathrm{g}} \phi\right) \\
& +\nabla \cdot\left[\mathbf{i}_{1}^{i}+\mathbf{i}_{\mathrm{g}}^{i}+\omega_{1}^{i} \rho_{\mathrm{l}} \mathbf{q}_{\mathrm{l}}+\omega_{\mathrm{g}}^{i} \rho_{\mathrm{g}} \mathbf{q}_{\mathrm{g}}+\left(\omega_{1}^{i} \rho_{\mathrm{l}} S_{1}+\omega_{\mathrm{g}}^{i} \rho_{\mathrm{g}} S_{\mathrm{g}}\right) \phi \frac{\mathrm{d} \mathbf{u}}{\mathrm{d} t}\right]=f^{i}
\end{aligned}
$$

The use of the material derivative leads to

$$
\begin{gathered}
\phi \frac{D_{\mathrm{s}}\left(\omega_{1}^{i} \rho_{\mathrm{l}} S_{1}+\omega_{\mathrm{g}}^{i} \rho_{\mathrm{g}} S_{\mathrm{g}}\right)}{D t}+\left(\omega_{1}^{i} \rho_{\mathrm{l}} S_{1}+\omega_{\mathrm{g}}^{i} \rho_{\mathrm{g}} S_{\mathrm{g}}\right) \frac{D_{\mathrm{s}} \phi}{D t} \\
+\left(\omega_{1}^{i} \rho_{\mathrm{l}} S_{1}+\omega_{\mathrm{g}}^{i} \rho_{\mathrm{g}} S_{\mathrm{g}}\right) \phi \nabla \cdot\left(\frac{\mathrm{d} \mathbf{u}}{\mathrm{d} t}\right) \\
+\nabla \cdot\left(\mathbf{i}_{1}^{i}+\mathbf{i}_{\mathrm{g}}^{i}+\omega_{1}^{i} \rho_{\mathrm{l}} \mathbf{q}_{\mathrm{l}}+\omega_{\mathrm{g}}^{i} \rho_{\mathrm{g}} \mathbf{q}_{\mathrm{g}}\right)=f^{i}
\end{gathered}
$$

The mass balance of solid is introduced in the mass balance of a component to obtain, after some algebra,

$$
\begin{aligned}
& \phi \frac{D_{\mathrm{s}}\left(\omega_{1}^{i} \rho_{1} S_{1}+\omega_{\mathrm{g}}^{i} \rho_{\mathrm{g}} S_{\mathrm{g}}\right)}{D t}+\left(\omega_{1}^{i} \rho_{\mathrm{l}} S_{1}+\omega_{\mathrm{g}}^{i} \rho_{\mathrm{g}} S_{\mathrm{g}}\right) \frac{1-\phi}{\rho_{\mathrm{s}}} \frac{D_{\mathrm{s}} \rho_{\mathrm{s}}}{D t} \\
& \quad+\left(\omega_{1}^{i} \rho_{1} S_{\mathrm{l}}+\omega_{\mathrm{g}}^{i} \rho_{\mathrm{g}} S_{\mathrm{g}}\right) \nabla \cdot\left(\frac{\mathrm{d} \mathbf{u}}{\mathrm{d} t}\right) \\
& \quad+\nabla \cdot\left(\mathbf{i}_{1}^{i}+\mathbf{i}_{\mathrm{g}}^{i}+\omega_{1}^{i} \rho_{\mathrm{l}} \mathbf{q}_{\mathrm{l}}+\omega_{\mathrm{g}}^{i} \rho_{\mathrm{g}} \mathbf{q}_{\mathrm{g}}\right)=f^{i}
\end{aligned}
$$

The volumetric deformation term $\left(\mathrm{d} \varepsilon_{\mathrm{v}} / \mathrm{d} t=\nabla \cdot(\mathrm{du} / \mathrm{d} t)\right)$ couples the mass balance equations with the deformation of the porous medium. This requires the coupled solution of the mechanical equations. The momentum balance for the porous medium reduces to the equilibrium of stresses if the inertial terms are neglected:

$$
\nabla \cdot \boldsymbol{\sigma}+\mathbf{b}=\mathbf{0}
$$

where $\boldsymbol{\sigma}$ is the stress tensor and $\mathbf{b}$ is the vector of body forces.

In addition, the balance of energy is introduced in the case of nonisothermal conditions. The equation for internal energy balance for the porous medium is established, taking into account the internal energy of each phase $\left(E_{\mathrm{s}}, E_{1}, E_{\mathrm{g}}\right)$, as

$$
\begin{aligned}
& \frac{\partial}{\partial t}\left[E_{\mathrm{s}} \rho_{\mathrm{s}}(1-\phi)+E_{\mathrm{l}} \rho_{\mathrm{l}} S_{\mathrm{l}} \phi+E_{\mathrm{g}} \rho_{\mathrm{g}} S_{\mathrm{g}} \phi\right] \\
& \quad+\nabla \cdot\left(\mathbf{i}_{\mathrm{c}}+\mathbf{j}_{E_{\mathrm{s}}}+\mathbf{j}_{E_{1}}+\mathbf{j}_{E_{\mathrm{g}}}\right)=f^{Q}
\end{aligned}
$$

where $i_{\mathrm{c}}$ is the energy flux due to conduction through the porous medium; the other fluxes $\left(\mathbf{j}_{E_{\mathrm{s}}}, \mathbf{j}_{E_{1}}, \mathbf{j}_{E_{\mathrm{g}}}\right)$ are advective fluxes of energy caused by mass motions; and $f^{\mathrm{Q}}$ is an internal/external energy supply. The use of the material derivative allows an equation to be obtained that is formally similar to the mass balance of components.

The simultaneous solution of the coupled equations given above produces the spatial and temporal evolution of displacements, liquid pressure, gas pressure and temperature, which are considered as state variables or unknowns in this approach.

\section{NOTATION}

$A$ parameter in gas relative permeability function (-)

$a_{s}$ parameter for linear swelling $\left(\mathrm{MPa}^{-1}\right)$

$b$ aperture (m)
$E$ Young's modulus (MPa)

$E_{\alpha}$ internal energy for $\alpha$-phase $(\mathrm{J} / \mathrm{kg})$

$f$ source term in balance equations $\left(\mathrm{kg} / \mathrm{m}^{3} / \mathrm{s}\right)$

$G$ Shear modulus (MPa)

$g$ gravity $(\mathrm{MN} / \mathrm{kg})$

i mass or energy flux $\left(\mathrm{kg} / \mathrm{m}^{2} / \mathrm{s}\right.$ or $\left.\mathrm{J} / \mathrm{m}^{2} / \mathrm{s}\right)$

j mass or energy flux $\left(\mathrm{kg} / \mathrm{m}^{2} / \mathrm{s}\right.$ or $\left.\mathrm{J} / \mathrm{m}^{2} / \mathrm{s}\right)$

$K$ permeability or hydraulic conductivity $(\mathrm{m} / \mathrm{s})$

$K$ Bulk modulus (MPa)

$k$ intrinsic permeability $\left(\mathrm{m}^{2}\right)$

$\mathbf{k}$ intrinsic permeability tensor $\left(\mathrm{m}^{2}\right)$

$k_{r} \quad$ relative permeability (-)

$k_{s} \quad$ swelling/shrinkage coefficient (-)

$k_{\text {suction }}$ parameter for cohesion induced by suction $\left(\mathrm{MPa}^{-1}\right)$

$M \quad$ Slope of critical state line (-)

$n$ number of fractures (-)

$n_{\alpha}$ parameter in relative permeability function for $\alpha$-phase (-)

n unit vector parallel to the discontinuity (-)

$P$ parameter in Van Genuchten model (MPa)

$p_{\alpha} \quad$ pressure in $\alpha$-phase (MPa)

$p_{a t m}$ atmospheric pressure (MPa)

$p_{o}$ pre-consolidation stress $(\mathrm{MPa})$

$p_{o}^{*}$ pre-consolidation stress for saturated soil $(\mathrm{MPa})$

$p_{s}$ tensile strength (MPa)

$Q$ flow rate $\left(\mathrm{m}^{3} / \mathrm{s}\right)$

$\mathbf{q}_{\alpha}$ flux vector for $\alpha$-phase $(\mathrm{m} / \mathrm{s})$

$q$ deviatoric stress (MPa)

$r$ curvature radius $(\mathrm{m})$

$S_{\alpha}$ degree of saturation for $\alpha$-phase (-)

$s$ element size $(\mathrm{m})$

T intrinsic transmisivity tensor $\left(\mathrm{m}^{3}\right)$

u displacement vector $(\mathrm{m})$

$\gamma(t)$ function of time $(\mathrm{kg} / \mathrm{MPa} / \mathrm{s})$

$\varepsilon$ normal strain (-)

$\varepsilon_{o} \quad$ strain parameter (-)

$\varepsilon_{1} \quad$ strain parameter (-)

$\varepsilon_{v} \quad$ volumetric strain (-)

$\lambda$ parameter in Van Genuchten model (-)

$\lambda$ Isotropic elasto-plastic compression index (-)

$\lambda(0) \quad$ Isotropic elasto-plastic compression index for saturated soil (-)

$\mu_{\alpha} \quad$ viscosity of $\alpha$-phase $(\mathrm{MPa} \times \mathrm{s})$

$\rho_{\alpha}$ density of $\alpha$-phase $\left(\mathrm{kg} / \mathrm{m}^{3}\right)$

$\phi$ porosity (-)

$\sigma_{t}$ Tensile strength (MPa)

$\sigma$ Surface tension $(\mathrm{N} / \mathrm{m})$

$v$ Poisson's ratio (-)

$\psi$ capillary pressure or suction $(\mathrm{MPa})$

$\omega$ mass fraction $(\mathrm{kg} / \mathrm{kg})$

\section{REFERENCES}

Alonso, E. E. \& Ledesma, A. (eds) (2005). Advances in understanding engineered clay barriers. Leiden: Balkema.

Alonso, E. E., Gens, A. \& Josa, A. (1990). A constitutive model for partially saturated soils. Géotechnique 40, No. 3, 405-430.

Alonso, E. E., Olivella, S. \& Delahaye, C. (2002). Gas migration in clays. In Environmental geomechanics (eds L. Vulliet, L. Laloui and B. Schrefler), pp. 83-94. Lausanne: Presses Polytechniques et Universitaires Romandes.

Alonso, E. E., Olivella, S. \& Arnedo, A. (2006). Mechanism of gas transport in clay barriers. J. Iberian Geol. 32, No. 2, 175-196.

Datta, R., Barr, D. \& Boyle, W. (2004). Measuring thermal, hydrological, mechanical, and chemical responses in the Yucca Mountain Drift Scale Test. In Coupled T-H-M-C processes in geo-systems: Fundamentals, modelling, experiments and applications (eds O. Stephansson, J. A. Hudson and L. Jing), pp. 155160. Oxford: Elsevier.

DIT-UPC (2000). CODE_BRIGHT. A 3-D program for thermohydro-mechanical analysis in geological media. User's guide. Barcelona: Centro Internacional de Métodos Numéricos en Ingeniería (CIMNE).

Enresa (2000). FEBEX Project, full scale engineered barriers experiment for a deep geological repository for high level radio- 
active waste in crystalline host rock. Final Report. Madrid: Enresa.

Gallé, C. (2000). Gas breakthrough pressure in compacted Fo-Ca clay and interfacial gas overpressure in waste disposal context. Appl. Clay Sci. 17, Nos 1-2, 85-97.

Gens, A., Carol, I. \& Alonso, E. E. (1995). Rock joints: FEM implementation and applications. In Mechanics of geomaterial interfaces, pp. 395-420. Elsevier.

Gens, A., Olivella, S. \& Valleján, B. (2001). Analysis of gas phase transport phenomena in compacted clay barriers. Proc. 10th Int. Conf. Comp. Methods Adv. Geomech., Tucson, AZ, 735-742.

Graham, J., Halayko, K. G., Hume, H., Kirkham, T., Gray, M. \& Oscarson, D. (2002). A capillarity-advective model for gas break-through in clays. Engng Geol. 64, Nos 2-3, 273-286.

Harrington, J. F. \& Horseman, S. T. (1997). Gas migration in clay. In PEGASUS: Project on the Effect of Gas in Underground Storage Facilities for Radioactive Waste, Proceedings of a Workshop, Mol, Belgium, 28-29 May 1997, EU Document X11/297/ 97-EN, pp. 155-174. Stockholm: SKB.

Harrington, J. F. \& Horseman, S. T. (2003). Gas migration in KBS3 buffer bentonite: Sensitivity of test parameters to experimental boundary conditions, SKB Technical Report TR 03-02. Stockholm: SKB.

Horseman, S. T, Harrington, J. J. \& Sellin, P. (1999). Gas migration in clay barriers. Engng Geol. 54, No. 2, 139-149.

Kickmaier, W., Yamamoto, S., Weber, H. P., Kaku, K. \& Gassler, W. (2002). GMT/IR 01-02: Construction of engineered barrier system. As-built report, Project Report 01-26. Wettingen, Switzerland: NAGRA.

Lanyon, G. W. (2001). GMT/IR 00-04: Conceptual model of flow in the geosphere and EBS for the GMT Experiment (Step B). March 2001, Project Report 01-08. Wettingen, Switzerland: NAGRA.

Lanyon, G. W. \& Vomvoris, S. (2002). GMT/M 01-31: GMT subtask modelling: Proposed test protocol. GTS Phase V/GMT, AN 02-076. Wettingen, Switzerland: NAGRA.

Lanyon, G. W., Marschall, P., Fukaya, M., Croisé, J., Yamamoto, S. \& Mayer, G. (2001a). GMT/IR 00-01. Laboratory data compilation report, January 2001, Project Report 00-20. Wettingen, Switzerland: NAGRA.

Lanyon, G. W., Marschall, P. \& Vomvoris, S. (2001b). GMT/M 0109: Saturation phase outline test plan. 17 July 2001, AN01-217. Wettingen, Switzerland: NAGRA.

Lee, H. S. \& Chou, T. F. (2002). Hydraulic characteristics of rough fractures in linear flow under normal and shear load. Rock Mech. Rock Engng 35, No. 4, 299-318.

Marschall, P., Fukaya, M., Croisé, J., Yamamoto S. \& Mayer, G. (2001). GMT/IR 00-01. Laboratory data compilation report, Project Report 00-20. Wettingen, Switzerland: NAGRA.

Olivella, S. \& Alonso, E. E. (2002). Modelling of gas flow in deformable clay stone formations, Monterri Technical Note TN 2002-40. Wettingen, Switzerland: NAGRA.

Olivella, S. \& Alonso, E. E. (2004). Modelling the hydro-mechanical behaviour of GMT in situ test including interface elements, GMT Report. Wettingen, Switzerland: NAGRA.

Olivella, S. \& Gens, A. (2005). Double structure THM analysis of a heating test in a fractured tuff incorporating intrinsic permeability variations. Int. J. Rock Mech. Mining Science 42, Nos 5-6, 667-669

Olivella, S., Gens, A., Carrera, J. \& Alonso, E. E. (1995). Numerical formulation for a simulator (CODE_BRIGHT) for the coupled analysis of saline media. Engng Comput. 13, No. 7, $87-112$.

Olivella, S., Carrera, J., Gens, A. \& Alonso, E. E. (1994). Non isothermal multiphase flow of brine and gas through saline media. Transport in Porous Media, 15, No. 3, 271-293.

Olsson, R. \& Barton, N. (2001). An improved model for hydromechanical coupling during shearing of rock joints. Int. J. Rock Mech. Mining Sci. 38, No. 3, 317-329.
Pusch, R. \& Forsberg, T. (1983). Gas migration through bentonite clay, SKBF/KBS Technical Report TR 83:71. Stockholm: SKB.

Pusch, R., Ranhagen, L. \& Nilden, K. (1985). Gas migration through Mx80 bentonite, NAGRA Technical Report NTB-85-36. Wettingen, Switzerland: NAGRA.

Renner, J., Hettkaamp, T. \& Rummel, F. (2000). Rock mechanical characterization of an argillaceous host rock of a potential radioactive waste repository. Rock Mech. Rock Engng 33, No. 3, $153-178$.

Romero, E., Alonso, E. E. \& Knobelsdorf, J. (2002a). GMT/IR 0106. Laboratory tests on compacted sand-bentonite buffer material for the GMT Emplacement Project, NAGRA Project Report 02-05. Wettingen, Switzerland: NAGRA.

Romero, E., Castellanos, E. \& Alonso, E. E. (2002b). Lead nitrate tests on compacted sand-bentonite buffer material. GMT Emplacement Project, NAGRA Report. Wettingen, Switzerland: NAGRA.

Romero, E., García, I. \& Alonso, E. E. (2003). Gas tests on compacted sand-bentonite buffer material. GMT Emplacement Project. NAGRA Report. Wettingen, Switzerland: NAGRA.

Rummel, F. \& Weber, U. (2000). GS experiment: Rock-mechanical testing on gasfrac self-healing effect, Mont Terri Project TN99-36.

Rutqvist, J., Barr, D., Datta, R., Gens, A., Millard, A., Olivella, S. Tsang, C.-F. \& Tsang, Y. (2005). Coupled thermo-hydro-mechanical analysis of the Yucca Mountain Drift Scale Test: comparison of field results to predictions of four different models. Int. J. Rock Mech. Mining Sci. 42, Nos 5-6, 680-697.

Senger, R. (2002). GMT/M 01-33: TOUGH2 Design modelling of Stages 1 through 4 saturation and subsequent gas injection. 18 April 2002, AN 02-082. Wettingen, Switzerland: NAGRA.

Tanai, K., Kanno, T. \& Gallé, C. (1997). Experimental study of gas permeabilities and breakthrough pressures in clays. Proceedings of a symposium on the scientific basis for nuclear waste management. Boston: Materials Research Society, 465, 9951002 .

Trick, T. (2002). GMT/M 02-17: GTS-GMT water test 1: RI-1. Project FLG/GMT, AN 02-254. GMT/M 02-20: GTS-GMT water test 1: RW-1 and RWSIN-1. Project FLG/GMT, AN 02-281. GMT/M 02-21: GTS-GMT water test 1: RI-2. Project FLG/GMT AN 02-282. GMT/M 02-22: GTS-GMT water test 1: CV RISin-1. Project FLG/GMT, AN 02-283. GMT/M 02-27: GTS-GMT water test 1: Layer1-RI and RW-1 and RWSin-1. Project FLG/GMT, AN 03-023. NAGRA. Switzerland: Solexperts.

Trick, T. (2003). GMT/M 03-05: RGI-1. GTS-GMT constant rate gas injection 1: RGI-1. Project FLG/GMT, AN 03-121. GMT/M 03-07. RGI-2a. GTS-GMT constant rate gas injection 1: RGI-2a. Project FLG/GMT, AN 03-132. GMT/M 03-08: RGI-2b. GTS-GMT constant rate gas injection 1: RGI-2b. Project FLG/GMT, AN 03-136. GMT/M 03-09: RGI-3a. GTS-GMT constant rate gas injection 1: RGI-3a. Project FLG/GMT, AN 03-137. Trick, T. (2002). GMT/M 03-12: RGI-3b. GTS-GMT constant rate gas injection 1: RGI-3b. Project FLG/GMT. AN 03-140. NAGRA. Switzerland: Solexperts.

Uehara, S. \& Shimamoto, T. (2004). Gas permeability evolution of cataclasite and fault gouge in triaxial compression and implications for changes in fault-zone permeability structure through the earthquake cycle. Tectonophysics 378, Nos 3-4, $183-195$.

Van Genuchten, M. Th. (1980). A closed-form equation for predicting the hydraulic conductivity of unsaturated soils. Soil Sci. Soc. Am. J. 49, No. 9, 892-898.

Volckaert, G., Ortiz, L., De Cannière, P., Put, M., Horseman, S. T., Harrington, J. F., Fioravante, V. \& Impey, M. (1994). Modelling and experiments on gas migration in repository host rocks, MEGAS Project, Final Report, Phase 1. Luxembourg: European Comission.

Zhang \& Rothfuchs (2004). Experimental study of the hydro-mechanical behaviour of the Callovo-Oxfordian argillite. Appl. Clay Sci. 26, Nos 1-4, 325-336. 